\title{
Barriers in repurposing an existing manufacturing plant: a total interpretive structural modeling (TISM) approach
}

\author{
Aadarsh Poduval ${ }^{1} \cdot$ Maruti Sriram Ayyagari $^{1} \cdot$ Mohit Malinda $^{1} \cdot$ Vimal K.E.K $^{2} \cdot$ Anil Kumar $^{3}$. \\ Jayakrishna Kandasamy ${ }^{1}$ (C)
}

Received: 29 April 2021 / Revised: 14 July 2021 / Accepted: 11 August 2021 / Published online: 13 October 2021

(c) The Author(s), under exclusive licence to Springer Science+Business Media, LLC, part of Springer Nature 2021

\begin{abstract}
Repurposing of an existing manufacturing plant is an emerging field due to the increase in emergencies of the covid-19 pandemic with the need of rapid responses which has a wide range of potential applications in sustainment of the manufacturing plant in these unfavourable times and helping of the economy. It makes the manufacturing plant adaptable to changes, makes it productive by manufacturing products that are currently in demand, prevents the dissolution of the plant and thus harvests the maximum potential of the manufacturing plant in the need of an emergency. However, not many industries and plants are suited to make the appropriate changes and lack knowledge on how to proceed to do so. The paper identifies the barriers that are faced in the transition for repurposing a general manufacturing plant to a more suited plant for current emergencies that need rapid response. These barriers hinder the repurposing of the manufacturing plant and impact the business decisions to establish a manufacturing plant suited for emergency situations. Surveys and information from various experts in this field are used to identify these barriers and document their interdependencies and influence on one another. The data is graphed and analysed utilizing TISM (Total Interpretive Structural Modelling) and MICMAC (Cross-Impact Matrix Multiplication Applied to Classification) methodology to further examine by classifying and ranking the relationships. Analysing the relationships between barriers leads to effective decisions towards the successful adoption of repurposing of manufacturing plant. A contextual relationship based structural table called interpretive table and structural model is made to pinpoint influential barriers. Thus, the research explains and explores significant barriers to the adoption of repurposing in manufacturing plant and not only provides a strong methodological and contextual contribution with the help of TISM and MICMAC but also gives research a sense of links of the barriers across various levels. On a practical level, the study is immensely useful to help manufacturing plants overcome repercussions due to disruptions by modifying existing practice and business model to a new model which synchronizes with the new normal to increase the efficiency and survivability of the plant. The result of the research points out that strategical, cultural, technological, and innovation barriers are the most influential barrier in repurposing of manufacturing plant.
\end{abstract}

Keywords Repurposing Manufacturing $\cdot$ Barriers · Total Interpretive Structural Modelling $\cdot$ MICMAC

Jayakrishna Kandasamy

mail2jaikrish@gmail.com

Aadarsh Poduval

aadarsh.poduval24@gmail.com

Maruti Sriram Ayyagari

marutiayyagari993@gmail.com

Mohit Malinda

mohitmalinda@gmail.com

Vimal K.E.K

vimalkek.engr@gmail.com
Anil Kumar

anilror@gmail.com

1 School of Mechanical Engineering, Vellore Institute of Technology, Vellore, Tamil Nadu, India

2 Department of Mechanical Engineering, National Institute of Technology, NIT-Patna, Bihar, India

3 Guildhall School of Business and Law, London Metropolitan University, London, UK 


\section{Introduction}

Covid-19, which was first reported in December 2019 and recognized by WHO as a pandemic in March 2020, has impacted the globe for over a year affecting all forms of goods and services. As of June 2020, the Coronavirus Resource Centre at Johns Hopkins University reported over 8.62 million infections and 485,706 deaths worldwide. The quarantine and lockdown operations led to international economic decline and have been a major blow to healthcare, manufacturing chains as a whole. In March 2020, US industrial production fell to its lowest since World War II while market in Europe plummeted to a new low. April 2020 saw a fall in car sales in the United Kingdom by 97 percent marking a new low since 1946.

Covid-19 pandemic has caused many manufacturing plants to close due to a lack of demand for the manufactured product. It has affected production processes thereby created delays for manufacturers, traders, individuals, endusers, and customers. Supply and demand factors have seen a radical change where the demand may have either dropped significantly or rapidly increased such that the production capacity may be unable to keep up (Rapaccini et al. 2020). Either cases call for the manufacturing plant to respond to market fluctuations to overcome disruptions triggered by emergencies. Manufacturing plants have to act quickly in sudden emergency to protect and help their employees as well as maintain operations that are critical lifelines for their consumers and communities. To identify problems and research requirements, focus should be made on factors such as dynamic regulations as well as manufacturing specifications while keeping in mind the modification of production process involved (Schumacher et al. 2021). It is found that development of a resilient system catered to emergency disruptions depends on capital investment as well as on existing rules and regulations.

Generally, it has been observed that transition of a firm's system and layout from product driven one to a service driven one supports production plants in addressing disruption. Despite this, manufacturing has been negatively affected, which can be linked to the magnitude of the pandemic and the immediate efforts made to minimize damage (Qin et al. 2021). Many manufacturing companies undertook a role in providing essential public and medical equipment and materials (Jain et al. 2020). Some manufacturers have successfully implemented repurposing i.e., methodology of manufacturers swiftly shifting to a new process or product. It has also been observed that many companies find repurposing difficult during the pandemic (Shokrani et al. 2020).

The pandemic has spurred research across a variety of fields. Studies to manufacturing during Covid-19 involves wide array of topics including additive manufacturing to mitigate damage, local case studies on production changes, industry 4.0 techniques etc. These establish manufacturing as a vital concern a pandemic or emergency environment. An appropriate example showcasing the same is observed in increasing demand of WHO approved PPEs as well as variety of healthcare resources and equipment (Prather et al. 2020).

In a detailed survey of 177 participants spread through Italian SMEs and large businesses, academics from Italy, Sweden, and Finland assessed the effect of the pandemic disruption on companies to build a management framework for emergencies (Rapaccini et al. 2020). Studies on low-level manufacturing innovations show that policies and strategies must follow accepted layouts and designs to contribute meaningfully to the industry (Armani et al. 2020). Other research looks at manufacturing from a supply chain risk and resilience perspective (Ivanov and Dolgui 2020). Manufacturing has a crucial role to play in a pandemic environment. In a COVID-19-like climate, few studies have documented the supportive enablers and obstructive barriers to manufacturing (Okorie et al. 2020). The situation of the Indian industry has been documented with multi-criteria decision analysis method to examine and categories local barriers as well as develop methods to address them. The results depict that, lack of technical expertise and training, lack of R\&D and innovation capabilities, popularity of traditional technology, high initial investment in latest technology, and fear of extra workload and loss of flexibility are some obstacles to sustainable development in Indian production firms (Gupta et al. 2020)

With the sudden emergence of the global pandemic, COVID-19, many industries and manufacturing plants have faced serious disruptions and, in many cases, have stop the production line as a result of low to zero demand of the manufactured product. While on one hand many industries have faced depressions, on the other hand they are industries that have thrived in this period and have been a staple example for other manufacturing plants in terms of repurposing their manufacturing system. One such indigenous example out of many has been the manufacturing of sanitizer from mahua flowers in Chhattisgarh which were previously used to make alcohol. Mahua flowers are grown by the tribes of Chhattisgarh with the purpose of producing alcohol. During the pandemic this manufacturing line was shifted to the manufacturing of sanitizers by utilizing the alcohol produced to meet the $>60 \%$ alcohol content in the sanitizers.

The quarantine $\&$ lockdown operation led to operational led to economic decline and it has been a major burden on manufacturing chains. That has caused multiple manufacturing plants undergo the scenarios such as lack of demand, Lack of trader individuals, End -users' customers. 
These are the few major issues in the Covid-19 pandemic:

- Supply Demand issues

- Only a Single Monopoly (In terms of recent product innovation such as PPE Kits, Self-testing Kit)

- In order to sustain radical changes to maintain a stability in operations

- Trying to create an environment where the market of Oligopoly over Monopoly

- Trying to reach out and connect sellers, purchase and procurement of the raw material

A possible solution to handle such disturbances in the manufacturing process may be adopted by manufacturing plants in the form of repurposing their existing model and modifying it to provide a different service and product that is in demand either due to need of the hour or disruption in other sectors. Repurposing is a method in which the existing manufacturing system or process is altered to adapt the disruptions caused. The process involves rethinking logistics, changes in manufacturing model change in tools equipment and labor, acquiring different raw material or altering the original raw material in terms of needs. The ideal was for repurposing is such that the existing model must be best utilized with minimum interaction from external organizations. However, to do so many manufacturing plants and industries face barriers (Barbeiri et al. 2020).

Repurposing differs from the traditional manufacturing method as the manufacturing process is modified, to develop a different output for the same input, in order to meet the changing demand. The factors and framework to this methodology have not been properly researched yet due to successful functioning of the existing framework (Shokrani et al. 2020). The novelty of repurposing and the tremendous potential in manufacturing plant applications motivates this research, which examines barriers in repurposing process. Manufacturing plants and industries. Examination of 80 cases in the covid 19 pandemic that have incorporated repurposing in the manufacturing and design segment has shown that inadequate design capability and flexibility of manufacturing are the hindrance to repurposing. (Liu et al. 2021).

In this case we are looking at a general manufacturing plant that incorporates all the basic and major functioning of a plant and the intention is to repurpose it to the emergency, requiring rapid response. In this regard, this research explores the following questions:

RQ1: What are the significant barriers to the repurposing an existing manufacturing plant?

RQ2: What are the interactions and contextual relationships between the barriers?
Additionally, the current study provides the readers with the basics of what is repurposing and highlights a simplified version of the process. Some developments in repurposing plants are also highlighted.

To address these research questions, the following objectives are defined.

RO1. To identify the barriers to repurposing manufacturing plants

RO2. To analyse and understand the causal relationship between the highlighted barriers

RO3. To develop a hierarchical model as per the driving power as well as dependency of the barriers over each other

The objective of the paper is to highlight barriers to repurposing of a manufacturing plant to the knowledge of manufacturing plant managers and business owners to repurpose the system in the most efficient way and to utilize the manufacturing plant to the maximum possible extent. The study involves identifying the barriers to repurposing an existing manufacturing plant, their interdependencies on one another and ranking them in terms of priority and interference on one another. The aim is to highlight the influential as well as dependent barriers in the plant. The study examines survey data from a number of manufacturing professionals and employees associated with the industry at the functional and management level. The barriers to repurposing are defined in the scope of COVID-19 disruption, with the assumption that they remain consistent across different regions as long as the context is limited to manufacturing sector during disruptions.

The following sections of the paper are structured as: Sect. 2 highlights on repurposing, describing its ability to manufacturing plants and reviews barriers to repurposing. Section 3 discusses the application of TISM in developing the model for examining barriers to repurposing. Consequently, MICMAC analysis is utilized to classify the highlighted barriers on the basis of their strength and dependence. Section 4 presents the results and discusses the barriers as well as highlights the limitations and elaborates on potential for future research. Section 5 concludes.

\subsection{Novelty of the study}

The paper identifies the barriers that are faced in repurposing a manufacturing plant to disruptions due to emergencies; the current Covid-19 pandemic being a prime example; to ensure survival and sustain operations. The novelty of the research rests in the fact that the results would provide immense help to plant managers in making effective decisions towards the successful adoption of repurposing of manufacturing plant. As a plant manager, they need to modify the existing operations, keep a check 
on all the specifications and make changes accordingly, need to see whether the production of new product can be done in the existing manufacturing systems, are the systems reconfigurable and making changes in business model so that supply and demand can be met easily without any hindrance.

\subsection{Case study}

The need of medical equipment's has increase especially ventilators since when the pandemic has begun in March 2020. People affected with corona virus, their lungs become so inflamed and full of fluid that they no longer deliver enough oxygen to the bloodstream to keep that person alive. One way to counteract this is by using a ventilator, which helps the patient's lungs operate while the rest of the body fights off the virus. To meet that shortfall, most ventilator companies started ramping up production as high as they could. Unfortunately, these devices are expensive and specialized and usually sold in small volumes. As such, it was a big stretch for many companies to tool up to produce as many as 10,000 per month. That is a lot for ventilators, but a drop in the bucket for what was predicted it was automotive companies that stepped up, or were called upon, to try to solve this. They know a lot about high volume manufacturing of complex devices, though not hospital grade devices.

Hero MotoCorp has also responded to this crisis by giving out 60 first-responder mobile ambulances. These are essentially motorcycling that also have a sidecar that has a sleeping arrangement for the patient along with basic healthcare equipment. These will be used in the rural regions of India. Many other manufacturers like HarleyDavidson are also helping their customers by providing extended warranty as well as home delivery of vehicles. Digital is the method almost all automakers are promoting. Customers are being asked to make online orders, with the option to test drive near their home as well as delivery at a preferred location. Pandemic has led to the shutdown of economies and due to stricter lockdowns movement of automobiles has drastically reduced which led to sharp decline in the profits earned by the companies in the terms of service and maintenance charges, priority-based services, sales profits etc. Here Automotive companies have used the manufacturing facilities and the complexity owned their facility has certainly helped the medical community to fight against the pandemic.

As this give us a clear picture on how the repurposing acts as a mitigation for enterprises and business who have to shut down too due to the uncertainty but, instead of shutting down making changes in the configuration of the systems in the production and assembly line and change of marketing and business strategy can definitely overcome this situation and hence repurposing is an effective solution.

\section{Literature review}

\subsection{Repurposing of manufacturing plants}

Emergencies like pandemics, natural disasters, wars etc. possess high amount of threat to manufacturing, characterized by instability as well as long-term disruptions in the system for producers, suppliers, and consumers. Disruption due to Covid-19 has mainly had two major effects on the industry- upset of already established and traditional plants, and disturbance in distribution networks led by fluctuation in the market. Many plants were forced to adopt a repurposing methodology to continue operations, targeting the growing demand in health and medical supplies including sanitizers and face masks.

The pandemic led to global economic disruption, while the sheer amount of infected and subsequent deaths highlighted inadequacies in the management framework pertaining to speedy production and delivery. The past year has reinforced the need for a core structure which embraces adoption of resilience strategies along with Industry 4.0 techniques to attain sustainability to deal with disruptions. It has shown the interplay between epidemic and Industry 4.0, specifically in the context of long-term workability and persistence during epidemic outbreaks. one encouraging direction of research is to assess industries' readiness level for Industry 4.0 and digitalization, and to propose a unanimous foundation for implementation of these technologies. Moreover, the concept of the viability of repurposing through these promising areas can integrate the resilience, sustainability, survivability, and robustness of pandemic-affected manufacturing unit (Farooq et al. 2021).

To repurpose the manufacturing plant will help the plant manage the immediate crisis and will be more consumer centered that will lead to growth of the plant as the economies recover. It will save the declining revenues of the plant because of low to no demand of the previously manufactured product by transitioning the plant to be well suited for the demand during the emergency. Repurposing will make the plant more resilient as it will lead to manufacturing of a new or similar product without much alteration in the resources used and in the manufacturing chain. It will lead to the production of the demanded product in a short span with minute changes in the manufacturing chain. In pandemic based climate, a corporation's primary concerns are to continue functioning, as well as protect employees. However, it has been observed in various firms that employee protection is lacking, leaving multiple 
employees to fend for themselves. This raises a barrier in repurposing termed in this paper as cultural barrier and where the employees are unwilling to implement the new strategies because of poor management. Surveys on manufacturing during the Covid-19 pandemic to bring out enablers and barriers based on review of the people who are actively engaged in the manufacturing plant also results in them feeling uncomfortable to adapt to the change in manufacturing chain mainly because of organizational flexibility (Hobbs 2020; Chowdhury et al. 2020). Apart from organizational challenges, the individual barrier was also mentioned as one of the prominent barriers in repurposing. (Okorie et al. 2020). Countries like the US and Europe, in programs like UNIDO and Ventilator Challenge program, have affirmed repurposing as an appropriate strategy to fulfil growing demand in healthcare industry (López-Gómez et al. 2020). Establishing repurposing entails altering work schedule, routes, and resources to fulfil new demand targets. Mass remodeling is an effective technique in the light of pandemic retardation. According to a research conducted in US, more than 2700 production plants operated by major corporations can be repurposed to make COVID19 essential products. As a result of COVID-19, several businesses have changed their manufacturing processes to produce critically needed products, such as perfume manufacturers moving to antiseptic gels, textiles factories producing face masks and medical gowns, and electronics producers producing respirators (Daniel et al. 2020).

\subsection{Barriers identified}

Barriers are any form of hindrance to the Repurposing of the manufacturing plant. Such type of block can affect the large part of the production process and dimmish the efficiency of the manufacturing plant. For smooth flow of operations and to utilize the manufacturing plant to the fullest it must be ensured that the barriers are identified and taken care of. Papers were searched from the databases of Scopus, Web of Science, Springer and Science direct and additionally reputed journal and reports were searched to retrieve articles based on the keywords, which include 'manufacturing', 'Repurposing', 'benefits', 'application' and 'barriers. Totally 11 major barriers were identified and grouped as tabulated in Table 1 with summary and descriptions.

\subsubsection{Strategic barrier}

Strategic decisions are one the most influential barrier that decides the survivability and viability of manufacturing plant especially in terms of repurposing. Clear motive with thorough research and with all-round information to carry out repurposing is needed. Unclear organizational goal with limited knowledge can slow down the speed, reduce efficiency and in extreme cases disrupt the manufacturing chain. No clear objective to start off the repurposing will lead to chaos, mismanagement and overall poor output for the manufacturing chain and this will eventually lead to the downfall of repurposing of the manufacturing and sometimes even the ongoing manufacturing chain of the plant. It is important to make sure that the complete strategy is well discussed with the experts and experienced personals in the respective fields and thorough research is done and must be executed accordingly. Though many people repurpose their manufacturing plant to meet the immediate emergencies such as the sudden increase in need of a new product or increase in the demand of the already manufactured product, it is important to strategic for a long-term goal. Short term goal and commitment will sometime lead to disruption later on. Long term strategic vision is important because the time frame of an emergency is very hard to evaluate and often wrong.

\subsubsection{Cultural barrier}

Though many manufacturing plant engineers and managers are quite curious on the adoption of repurposing the plant, they should also be willing to undertake the new experiments and are needed to do so. Unwillingness of top management to equip new technology, spend financially and relocate man power and materials will not lead to efficient adoption of repurposing technology. Not only the willingness of top management is important, the willingness of the whole team is important. People must be willing to accept the new roles given to them and under take the new project without hesitation. Though major manufacturing plant managers will be hesitant to take up new technologies and strategy for repurposing, startup plants and minor ones will be more open to do so. Moreover, organizational culture is a crucial part in terms of repurposing. It is a substantial decision to share the information and discuss the process of adoption strategies with raw material suppliers and consumer experts to broaden the scope for repurposing and be open to feedback and incorporation of suggested methods.

\subsubsection{Technological barrier}

Repurposing of a manufacturing plant chain is a complicated process with lots of intermediate steps and will vary form one manufacturing plant to another. It is important at such a time to incorporate the latest and the most useful technologies to ensure smooth adoption for repurposing. Having sufficient technology and a proper communication structure will help in the rapid communication and reduce 
Table 1 Barriers list along with their Descriptions and References

\begin{tabular}{|c|c|c|}
\hline Barrier & Description & References \\
\hline Strategic Barrier (B1) & $\begin{array}{l}\text { - Unclear organization objective } \\
\text { - No complete knowledge about the new repurposed model } \\
\text { - Short term decision making and goals }\end{array}$ & $\begin{array}{l}\text { - Okorie et al. (2020) } \\
\text { - Baig et al. (2020) } \\
\text { - Kumar and Vinodh (2020) } \\
\text { - Gaikwad et al. (2020) }\end{array}$ \\
\hline Cultural barrier (B2) & $\begin{array}{l}\text { - Unwillingness by the team to implement the repurposed manufacturing pro- } \\
\text { cess } \\
\text { - Refusal of information sharing between supply-partners, distributers, raw } \\
\text { material suppliers etc }\end{array}$ & $\begin{array}{l}\text { - Sindhwani et al. (2019) } \\
\text { - Alora and Barua (2019) } \\
\text { - Roy et al. (2021) }\end{array}$ \\
\hline Technological barrier (B3) & $\begin{array}{l}\text { - Lack of IT } \\
\text { - Inadequate framework of communication }\end{array}$ & $\begin{array}{l}\text { - Zhu et al. (2019) } \\
\text { - Karuppiah et al. (2020) } \\
\text { - Roy et al. (2021) }\end{array}$ \\
\hline Individual barrier (B4) & $\begin{array}{l}\text { - Lack of educated and skilled employees } \\
\text { - Inadequate resources, information and management skills }\end{array}$ & $\begin{array}{l}\text { - Mathivathanan et al. (2021) } \\
\text { - Karuppiah et al. (2020) } \\
\text { - Roy et al. (2021) }\end{array}$ \\
\hline Financial barrier (B5) & $\begin{array}{l}\text { - Little to no financial benefit } \\
\text { - Inadequate Capital to start the repurposed manufacturing plant } \\
\text { - Lack of Capital for the procurement of raw material }\end{array}$ & $\begin{array}{l}\text { - Jayan et al. (2020) } \\
\text { - Alora and Barua (2019) } \\
\text { - Karuppiah et al. (2020) } \\
\text { - Roy et al. (2021) }\end{array}$ \\
\hline Resource Barrier (B6) & $\begin{array}{l}\text { - Procurement and the lack of Men, Material and money } \\
\text { - Limited knowledge about the procurement of these }\end{array}$ & $\begin{array}{l}\text { - Okorie et al. (2020) } \\
\text { - Vogelsang et al. (2019) }\end{array}$ \\
\hline Regulatory Barrier (B7) & $\begin{array}{l}\text { - Environmental policies, Government policies and trade policies } \\
\text { - License to manufacture the product } \\
\text { - Subsidiary from the government }\end{array}$ & $\begin{array}{l}\text { - Sindhwani et al. (2019) } \\
\text { - Mathivathanan et al. (2021) } \\
\text { - Kumar and Vinodh (2020) }\end{array}$ \\
\hline Sourcing barrier (B8) & $\begin{array}{l}\text { - Handling of fluctuations in the supply and demand } \\
\text { - Constantly meeting the need of the customers } \\
\text { - Transportation from the supplier to the supplying of product/service }\end{array}$ & $\begin{array}{l}\text { - Bekaert et al. (2020) } \\
\text { - Baig et al. (2020) } \\
\text { - Roy et al. (2021) }\end{array}$ \\
\hline Innovation barrier (B9) & $\begin{array}{l}\text { - Lack of innovative methods to repurpose the manufacturing chain with minimum } \\
\text { interactions for the manufacturing or providing of goods and services } \\
\text { - How the existing manufacturing plant can be repurposed in the most efficient } \\
\text { way }\end{array}$ & $\begin{array}{l}\text { - Bauer et al. (2017) } \\
\text { - Mathivathanan et al. (2021) }\end{array}$ \\
\hline $\begin{array}{l}\text { Reconfigurable Manufac- } \\
\text { turing System (B10) } \\
\text { Quality Barrier (B11) }\end{array}$ & $\begin{array}{l}\text { - The lack of flexibility and agility of the repurposed manufacturing plant } \\
\text { - Lack of responsiveness of the manufacturing plant } \\
\text { - Lack of incorporation of Lean Manufacturing Methods } \\
\text { - Quality of the manufactured product or service not being on power with the } \\
\text { already existing ones in the market }\end{array}$ & $\begin{array}{l}\text { - Mattevi and Jones (2016) } \\
\text { - Kumar and Vinodh (2020) } \\
\text { - Urbinati et al. (2021) } \\
\text { - Gupta et al. (2020) } \\
\text { - Vogelsang et al. (2019) }\end{array}$ \\
\hline
\end{tabular}

delays and increase the overall efficiency. It will allow realtime update with the market and also helps predict what the future demand and supply curve will look like. Hence internal digital culture is important for the feasibility of repurposing.

\subsubsection{Individual Barrier}

Having enough man power is not only sufficient for the successful repurposing but quality of the man power and the knowledge they possess about the repurposing, having sufficient skills is equally important. These requirements are applicable from the top management to the workers. Management skills for the repurposing will determine the efficiency, delays and viability of the repurposed manufacturing plant. Skilled labor and skilled top level management authorities will have an impact of the manufacturing plant in terms of quality and time to manufacture.

\subsubsection{Financial barrier}

To allow the changes for proper repurposing necessitates additional investment. During emergencies and their aftermath, access to finance may be limited leading to search of alternate options for capital. Technology and financial barriers are significant while negotiations for changes are underway. The release of valuable corporate information to competitors serves as a tall barrier. Generally, SMEs must pay their supplier in advance, or shortly after delivery, while their clients seek payment of few days; resulting in locked capital. Businesses are currently poor while repurposing is an expensive methodology to implement.

\subsubsection{Resource barrier}

Before the pandemic, globally connected manufacturing chains were standard but businesses are now exploring 
transitioning to a much more localized manufacturing plant to ensure business continuity. Local manufacturing plants and industries have the benefit to prevent disruption due to external occurrences. Though there still exist practical and geographical limitations considering the fact that not every commodity can be produced in every location, an example being plant products which are climate dependent. Resource barriers consist of five elements- a lack of appropriate regulations, standards, economic instability, lack of external knowledge about sustainability, and large initial buyer/supplier investment. For repurposing, preliminary phase involves making a bill of materials and design drawings. Forming new partnerships makes sourcing of new raw materials a challenging task for manufacturers. Also, price fluctuations arise due to increase in competition for inputs. Exports from China have fallen due to pandemic, resulting in scarcity of critical parts; example being lack of pneumatic fittings, titanium, and some other critical components for medical devices.

\subsubsection{Sourcing barrier}

Value for money, being a significant sourcing factor results in strict contemplation of partners, by a company. It is observed that cases of dual sourcing may be more expensive than relying on a single source, but leads to long-term resilience for a firm. Companies must maintain such procurement of materials and contracting practices, which accommodate a complex buying conduct. Lack of resources, and increased pressure are the two elements of barriers on the supplier side. Also, lack of information of long-term demand, as well as of knowledge about new production environment leads to difficulty in assessing the risks of entering a new market. Manufacturers are hesitant in sharing proprietary information as they are afraid of competition from new market entrants once the pandemic is over. Development of sophisticated essential products is difficult when starting without any prior knowledge. Furthermore, increase in new entrants may lead to overproduction.

\subsubsection{Regulatory barrier}

Tariffs in border interaction are a known case of hindrance. Additionally, managing the current trade climate is especially difficult due to a number of technical and legal obstacles to transportation caused by Covid-19. Repurposing is followed by development of detailed manufacturing designs to detect possible issues. Certification evaluations as well as benchmarks differ with geographic location, as well as whether goods are manufactured for government operations or for the market. Modifications in benchmark standards via government create issues and confusion among firms. Another time-consuming process is the development of prototypes and verification data for proving quality and specifications of the product. The entire procedure can take weeks or even months to complete.

\subsubsection{Innovation Barrier}

This involve lack of innovative methods to repurpose the manufacturing chain with minimum interactions for the manufacturing or providing of goods and services as well as how the existing manufacturing plant can be repurposed in the most efficient way. As the technologies change keep changing at a short span of time and lack of updating the data generated manually each is time consuming. To get the work done efficiently certain principles are implemented due to which innovation barrier has been introduced. It is a critical element among all the barriers as it determines how the work should be done without affecting the current operations and advise on new shortcomings to improve the efficiency of the processes and business. Innovation barrier plays a major role as we are living the digital life as new technologies keep emerging quite frequently as we are into manufacturing business it is our utmost priority to update the existing technologies and implement new products and standards on a quick basis. Because as there is cut to throat competition throughout the global so in order to maintain a position and sustain in the respective industry innovation is highly significant and cannot be underlined as an ordinary barrier.

2.2.9.1 Reconfigurable manufacturing system This involves lack of flexibility and agility of the repurposed manufacturing plant as well as lack of responsiveness and incorporation of lean manufacturing methods. The same controls six principles- modularity, integrability, flexibility, convertibility and diagnosability. The repurposing of the existing manufacturing plant and the integral element of the manufacturing system is machines, tools, systems, software are need to be installed and uninstall while repurposing their business decisions. Manufacturing units need to develop their communication and interfaces to integrate various modules which require varies from business to business in a manufacturing plant. When the manufactures get systems for the processes operations, they need to maximize the systems efficiency and need to check the working of the system and needs to be upgrade on a timely basis in order to have a smooth flow of operations without any hindrance. For reconfiguring the systems, it is crucial to see that whether the systems, machine and tools have the capability to produce new products and help in the repurposing of an existing manufacturing plant. The systems are need to be make sure that that there can be any new lines of production to increase the maximum production. The sys- 
tems which are operational are adhering to requirements of the product manufactured and installed with latest software to continue the continuous work flow. Systems needs to detect errors and have necessary sensors to control any major hazardous events. Reconfigurable Manufacturing System is created for rapid change in the structure of a component in the manufacturing plant to quickly adjust the production line in accordance with sudden changes in the market.

2.2.9.2 Quality barrier Quality of the manufactured product or service not being on par with the already existing ones in the market. Quality is an important element of any product irrespective of the industry as quality is the top most priority of any product. It acts as a trust building and an innovative way to release the product into the market. Quality is basically a criterion to make sure that the product and the standard of something as measured against other things of a similar kind; the degree of excellence of something. Quality is about defining and meeting the needs of people by developing it for making the lives easier which will help to make the business flourish. Without the quality being in power with the already existing product or service in the market the demand will not be met.

\subsection{Need for TISM and MICMAC analysis}

Repurposing has been established as an appropriate method to stimulate an emergency management system with extended benefits to global manufacturing plants. Managers may make effective decisions for efficient manufacturing plant repurposing by understanding the relationships between barriers. There is lack of literature and studies that establish theory as well as create the mutual relationships between barriers despite. In summary, current literature evidence focuses on testing existing hypotheses or attempting to support previous literature, but fails to establish theory in terms of strategic framework. Hence, this paper focusses on bridging the gap by creating a performance model for the eleven barriers identified to repurposing by using a contextual relationship-based TISM approach and draws on the opinions of the relevant industrial experts.

TISM has an edge over the approached such as DOI (Diffusion of Innovation) theory and TOE (TechnologyOrganization-Environment) practice. DOI is helpful in predicting a company's introduction of newer technologies based on innovation and organizational characteristics while TOE describes factors that affect a company's ability to capitalize on new technologies. Both TOE and DOI cannot analyze the barriers that affect successful adoption. TISM as a method achieves this as well as follows the Pareto 80-20 theory to assist management in prioritizing the $20 \%$ of root barriers that influence $80 \%$ of the adoption process and obtain better opinions in the barrier removal processes.

Technology acceptance model (TAM) is an established model that is used to investigate emerging technology implementation and to gauge how companies feel about it. TAM offers interesting behavioral insights and in-depth knowledge but does not explore inter-relationships between adoption barriers which is discussed in TISM.

By explaining the transitive connections and the reasons behind the linkages between the elements of the interpretive structural modeling (ISM) based model, TISM also aims to generate a strategic theoretical framework to resolve the pitfalls of conventional ISM. TISM is an advancement over conventional ISM that is used to build a contextual relationship-based performance model for the barriers to effective repurposing of manufacturing plant. The method is an interpretive approach to modelling contextual relationships based on group judgments about the interaction of the various elements involved. The relationships are depicted via digraph such that the hierarchical order and direction of the relationships among the elements are represented by an arrow. The same is an advantage over conventional ISM, and it also has the benefit of allowing logical retrace of the transitive relations as TISM uses expert opinion to determine the true reason for transitivity only considering successful transitive links when designing the model. Hence, the final TISM model developed depicts only the effective links and gives a more accurate comparison of the elements.

TISM Model and repurposing processes go hand in hand as repurposing acts as a kick start or you could say a backup starter to restoring the operations and acts as an exigency management system within the global manufacturing units. In order to make effective decisions and improving the theory of the process's relationship and barriers are introduced in due course these terms help us to correlate, connect and make visualize the scenario of the operations in the unit. This certainly develops the effective decision making helps in bridging the gap of by creating a model-based system with eleven barriers playing a key role and identifying it through repurposing using TISM Model. The barriers are classified with MICMAC analysis, which is found on the idea that relationships are never identical-some may be strong while others may be weak. MICMAC analysis supports classifying barriers and defining the key elements that drive the structural model based on the strength of power (dominance) and mutual dependence among each barrier.

\subsection{Gaps identified from literature review}

With the growing concern of new outbreaks that lead to emergencies, many strategies and methods are adopted by manufacturing plants, industries and manufacturing chains 
to make them more resilient and viable so that they can adapt existing manufacturing line to the disruptions caused by emergencies and ensure the survivability of the manufacturing plant. Various research and studies have been done in area of flexibility, resilience and viability. Many studies and papers have been published to identify the barriers but not in terms of repurposing a manufacturing plant. There are very few studies discussing the barriers in repurposing of manufacturing system and have not been collectively and specifically identified for a manufacturing plant. Barriers and hindrance to these methods are identified and their impacts are discussed individually as separate studies but not in a collective manner. Solutions to tackle these barriers and avoid them have also been researched but prioritization of these barriers and ranking them based on their influence is lacking. Interrelationship between the barriers, their influence on one another and importance of identifying these relationships have not been done. There is no contextual based relation model to these barriers. There is a lack of research in categorizing and ranking the barriers in terms of priority, based on the influence and dependency on one another. Research has been done on repurposing supply chain and block chain technology, but no study has been done to identify the barriers for repurposing of an existing manufacturing plant.

\section{Research methodology}

This section involves mainly on the basis on how the study has been conducted what were the factors involved and surveys conducted, and expertise has been taken to get a depth of the problem and solving it efficiently. The primary part was the analyzing the barriers and the outputs of the repurposing manufacturing plant and try to find out the major barriers of the plant which are the cause of hindrance in the processes.

TISM Model initiates making the reachability and final reachability matrix which helps develops the relationships of each barrier according to the consideration by denoting 0 and 1 and a creation of webbed diagram completes the creation of TISM Model followed by MIMAC analysis which is done by plotting the graphs along with scatter points to determine the dependency and drivability powers. MIMAC analysis delivers a graphical representation of the barriers mentioned in lesser quadrants and interlinking the linkages of the barriers based on dependency and drivability power. In addition to that, expertise of the top individuals who are experienced in the field of repurposing and resilience through online surveys are gathered. The points mentioned were gathered from the experts and was said that the interactions and contextual relationships between the barriers and the significant roles impacting the repurposing Fig. 1.

\section{TISM and MICMAC analysis}

This section discusses the steps adopted to develop the TISM model. Then, by using MICMAC analysis the dependent, linkage and autonomous elements in the system are identified. The step-by-step procedure involved is highlighted in the following sub-sections. TISM Model helps to link all the interactions and barriers and see which of the barriers are affecting the repurposing processes and study the behavior of the barriers which are linked with TISM and segregate accordingly. TISM Model and repurposing processes go hand in hand as repurposing acts as a kick start or you could say a backup starter to restoring the operations and acts as an exigency management system within the global manufacturing units. In order to make effective decisions and improving the theory of the processes relationships and barriers are introduced in due course these terms help us to correlate, connect and makes visualize the scenario of the operations in the unit. This certainly develops the effective decision making helps in bridging the gap of by creating a model-based system with eleven barriers playing a key role and identifying it through repurposing using TISM Model.

\subsection{Applying TISM method}

In this section, the basic steps of TISM methodology are described to create the required relationship-based model to examine barriers to manufacturing. Each stage is documented, along with the information obtained during the development of the TISM model. While we were in the processes of procuring the data, we had series of brainstorming sessions with experts who had a glorious and appreciated experience of 7-10 years. They are highly educated and have been stakeholders in multinational companies and we have interacted with them and have taken their inputs.

Step-1. Identifying and defining the elements: The first step is collecting observations and data. For this scenario, several barriers towards repurposing a manufacturing plant are identified from available literature and studies. The TISM model is to be developed for these elements. The literature is used to highlight the different barriers with frequent discussions to formulate rationale behind selection of each. Eleven barriers are identified, which include strategic (B1), cultural (B2), technological (B3), individual (B4), financial (B5), resource (B6), regulatory (B7), sourcing (B8), innovation (B9), reconfigurable manufacturing system (B10) and quality barrier (B11). These are further analyzed with expert help.

For the study, respondents were asked to provide answers to a questionnaire and justify logic behind each barrier. The same was referenced to document the potential effect of each barrier on repurposing a plant. Moreover, the cause of each barrier was also assessed to gain a better understanding of 
Fig. 1 Methodology adopted

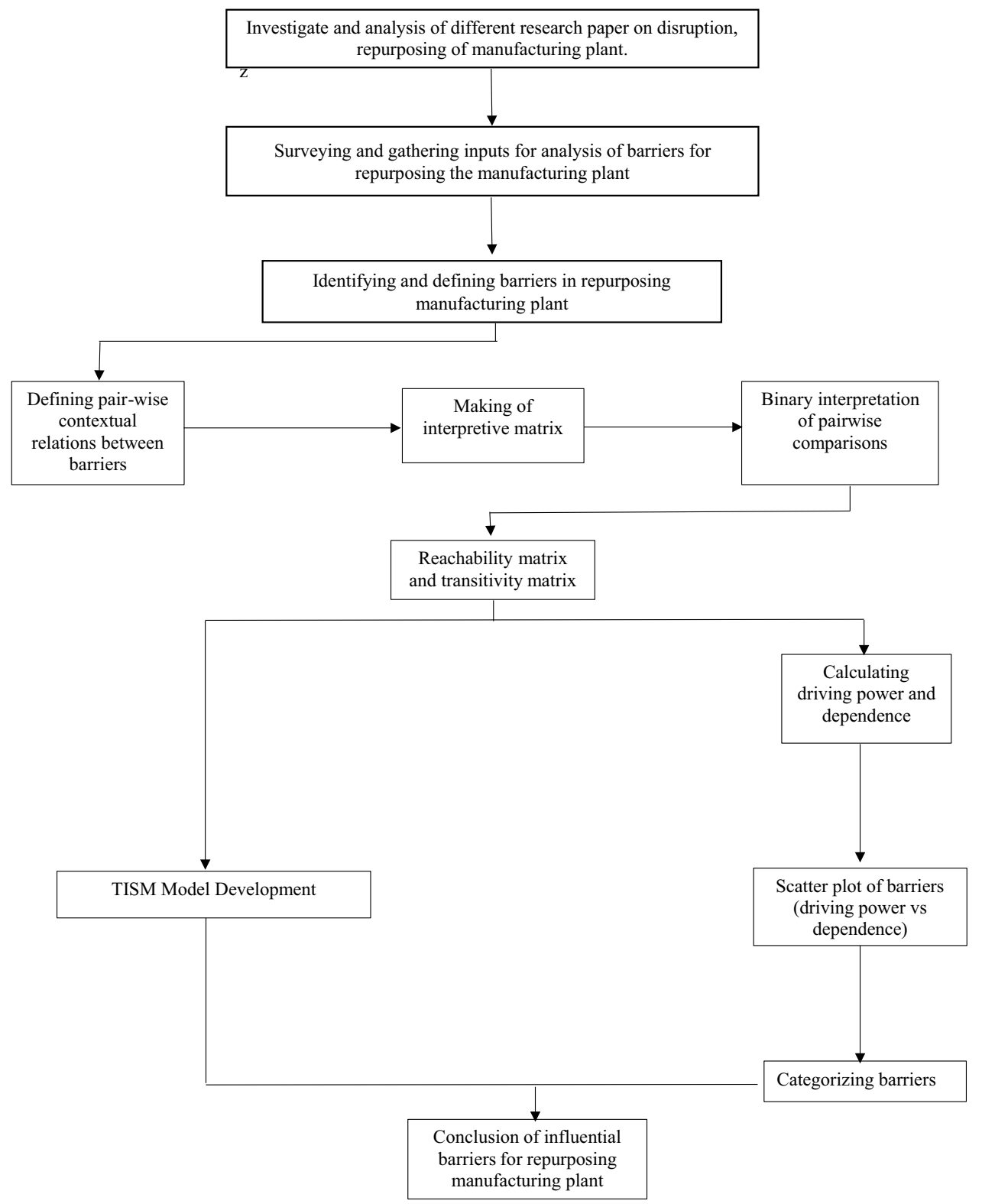

the driving elements of practical repurposing. Focus was aimed at industrial experts who had opportunity as well as experience in tackling the domain of the study. A thorough description of each barrier was provided to them to enable them to respond appropriately for the model.

Step-2. Defining contextual relationships: This step aims to determine the contextual relationships that exist between the barriers. A pair-wise relation chart was developed with the help of expert opinion and brainstorming sessions. The chart defines if a Barrier B1 will influence another Barrier B2, and so on, along with the corresponding interpretation. The analysis of how Barrier $B_{i}$ influences Barrier $B_{j}$ is documented, along with the logical reasons to create a knowledge base. Expert opinion was sought to define contextual relationships among the barriers for progress in study.
In study, the potential relationships were understood, and the knowledge base so created is tabulated. For any conflicting responses, a positive answer with a 50\% ratio led to noting that relationship else it was set as negative. All positive responses indicate a relationship between the corresponding barriers and the explanations made with expert help frame conclusions and tabulate the same. The pair-wise contextual relationships among barriers B1 to B11 are depicted in Table 2.

Step-3. Binary interpretation of pair-wise comparisons: The logical interpretation of the Yes/No relationship between the compared barriers are entered in a ' $\mathrm{x}$ n' matrix where, $\mathrm{n}$ is the number of barriers considered in the study. For each (i,j) the cell, the value of either ' 1 ' or ' 0 ' is entered based on the influence of barrier $\mathrm{Bi}$ over the barrier $\mathrm{Bj}$ where 


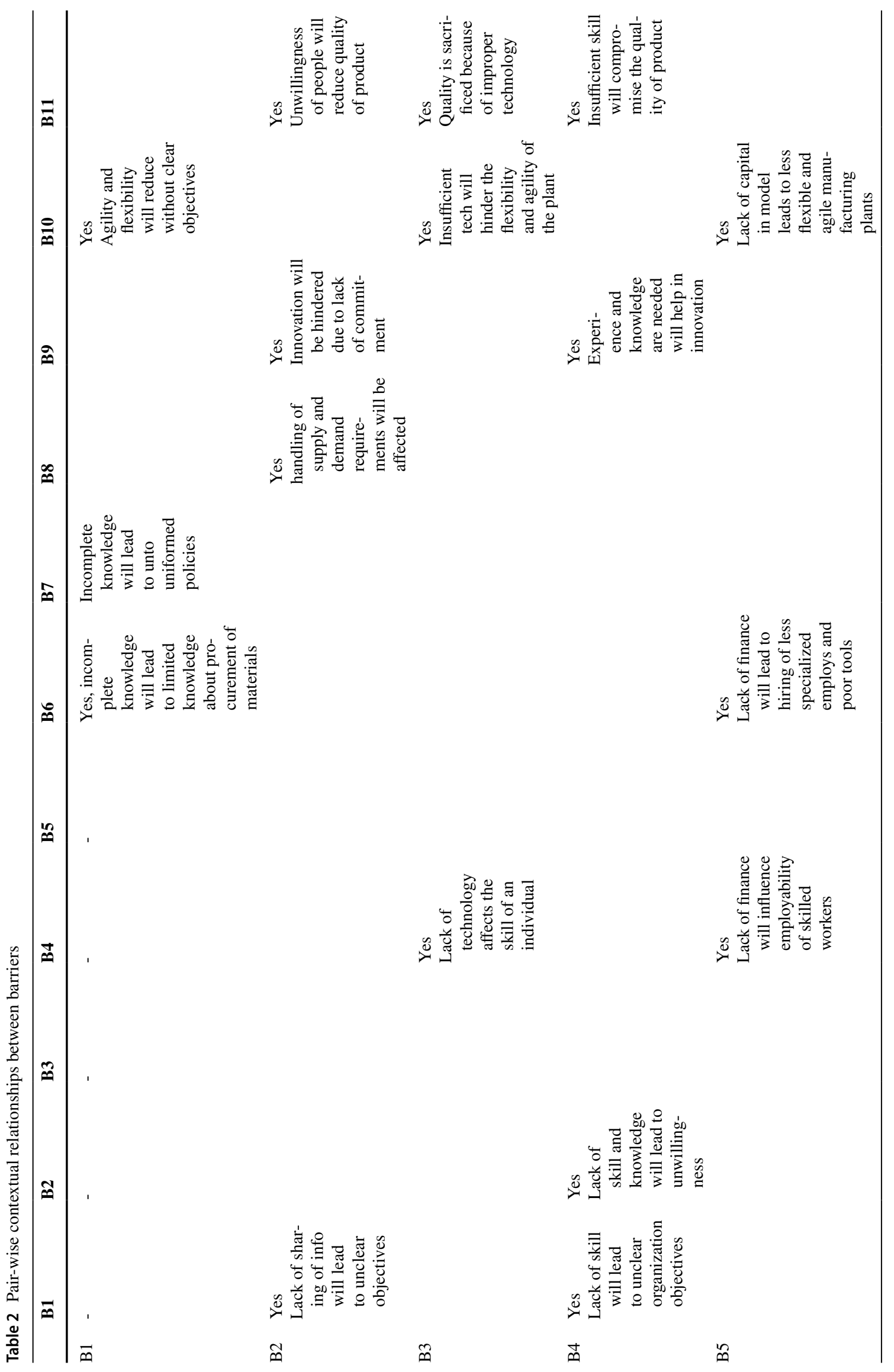




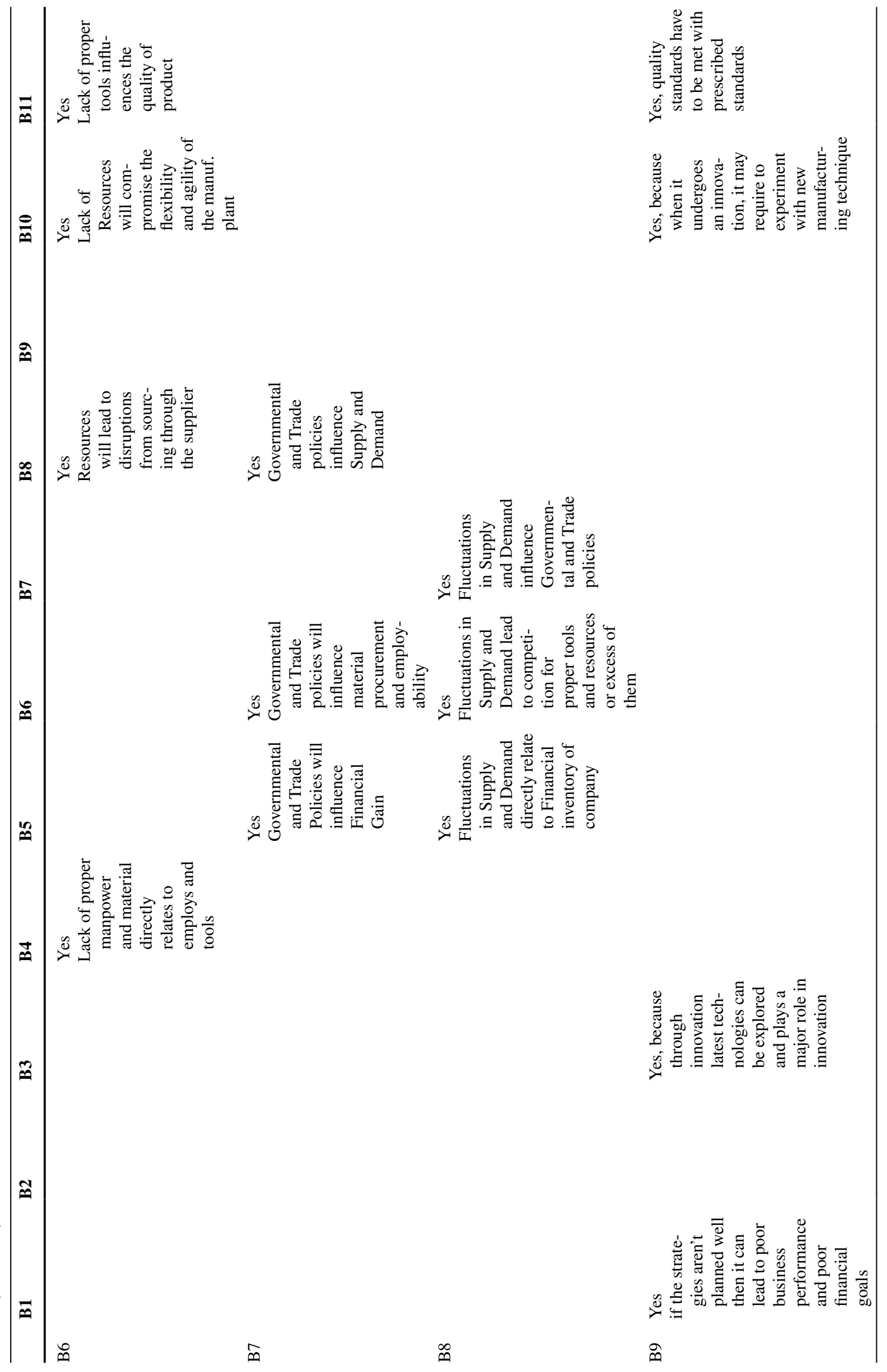




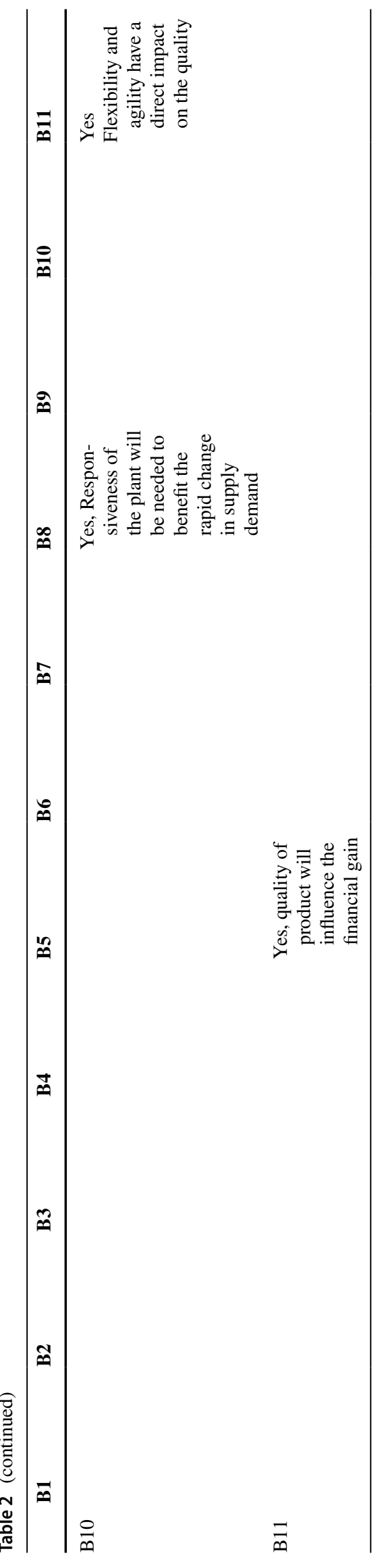

' 1 ' depicts the presence of influential relationship of Bi over $\mathrm{Bj}$ and ' 0 ' denoting the absence of a relationship. A $11 \times 11$ matrix totaling 110 comparisons is made.

Based on the tabulated study, development of the initial reachability matrix. The comparisons are represented as a matrix with each element except the diagonal elements carrying binary values ' 1 ' or ' 0 '. The value ' 1 ' is given in the cells if the logic knowledge base shows any existing relationship between the compared barriers, otherwise value ' 0 ' is entered. The initial matrix is depicted in Table 3.

Step-4. Transitivity check: The initial reachability matrix is examined for any possible indirect relations based on the transitivity rule- "if Bx influences By and By influences Bz, then $B x$ influences $B z$ ". For any positive transitive link, the tabulated study is modified and the elements influencing said transitive relationship are inputted. Only the transitive relationships with a major influence are taken into account, with the remainder being overlooked. Transitive relations are identified, and the final reachability matrix obtained is shown.

An example of transitive relation is that which exist between B1 (strategic) and B4 (individual) which did not exist in the initial matrix but TISM observes that flaws in decision making would lead to obstacles in procuring properly skilled and sufficient employees, thereby affecting the industry at the individual (personnel) level. The transitivity among barriers is tabulated and shown in Table 4 .

The transitive relations are examined by the same experts. A study for the transitive links is derived and Table 4 is revised based on their inferences. Since not all transitive links are effective, those found to be so are removed. The same depicts one of the most significant benefits of a TISM model- "In regular ISM the transitive relations are formed based just on the transitivity rule (Girubha et al. 2016) but in case of TISM the logic behind the transitivity is examined and the effective links alone are considered for further study". The barriers responsible for each transitive link are identified and documented. The next phase involves further analysis of the transitive nature. Each link is studied individually and the nature of transitivity is inferred to update the study. The final matrix before TISM model is shown in Table 5 .

Step-5. Level partitions: A level-wise partitioning of the barriers is done to identify the hierarchy placement of the barriers. The reachability, antecedent and intersection are calculated and arranged according to the driving power and dependency of each barrier, formulating the backbone of the digraph of the TISM model as shown in Fig. 2.

The previous step provides the final reachability matrix, which is made up of entries on pairwise assessments due to direct relationships together with some of the entries derived from inferred transitive relationships i.e., the effective transitive relationships. Barriers with similar intersection and 
Table 3 Initial reachability matrix

\begin{tabular}{|c|c|c|c|c|c|c|c|c|c|c|c|}
\hline & B1 & B2 & B3 & B4 & B5 & B6 & B7 & B8 & B9 & B10 & B11 \\
\hline B1 & & & & & & 1 & 1 & & & 1 & \\
\hline B2 & 1 & & & & & & & 1 & 1 & & \\
\hline B3 & & & & 1 & & & & & & 1 & 1 \\
\hline B4 & 1 & 1 & & & & & & & 1 & & 1 \\
\hline B5 & & & & 1 & & 1 & & & & 1 & \\
\hline B6 & & & & 1 & & & & 1 & & 1 & 1 \\
\hline B7 & & & & & 1 & 1 & & 1 & & & \\
\hline B8 & & & & & 1 & 1 & 1 & & & & \\
\hline B9 & 1 & & 1 & 1 & & & & & & 1 & 1 \\
\hline B10 & & & & & & & & 1 & & & 1 \\
\hline B11 & & & & & 1 & & & & & & \\
\hline
\end{tabular}

reachability set are designated to the topmost level (Level I) and the Level I barriers are removed from the entire set for the next iteration. The process is continued until each barrier is assigned their corresponding levels. Finally, after 4 iterations all the elements are assigned their levels.

Step-6. Developing TISM model: Barriers are arranged diagrammatically based on their levels while links between the barriers are represented in terms of arrows pertaining to the data in the final reachability matrix. The TISM model for the study is hence developed.

Solid arrows depict direct relationship and Blue dashes depict transitive relation. The TISM model for the study is shown as Fig. 3.
Step-7. Validating the TISM model: The TISM model developed is not final and is to be assessed by the help of the experts contacted before for the study. 81 relations between the barriers were established. Experts were presented with relation of each barrier that had been established and were asked to grade the barrier relation on the scale of 1-5 with 5 being that they strongly agree with the barrier relation. If the average grade of the relation is less than 3.5 then the relation is not recorded and removed from the TISM model. Table 6 shows the score given by each of the 10 experts on the relations. From the table it is clear that all relations in the TISM model are valid and over score of the TISM model developed is 4.21. The final validated TISM model is depicted in Fig. 4.
Table 4 Elements providing transitivity

\begin{tabular}{|c|c|c|c|c|c|c|c|c|c|c|c|}
\hline & B1 & B2 & B3 & B4 & B5 & B6 & B7 & B8 & B9 & B10 & B11 \\
\hline B1 & & & & B6 & B7 & & & $\begin{array}{l}\text { B6 } \\
\text { B7 } \\
\text { B10 }\end{array}$ & & & $\begin{array}{l}\text { B6 } \\
\text { B10 }\end{array}$ \\
\hline B2 & & & B9 & B9 & $\begin{array}{l}\text { B8 } \\
\text { B11 }\end{array}$ & $\begin{array}{l}\text { B1 } \\
\text { B8 }\end{array}$ & $\begin{array}{l}\text { B1 } \\
\text { B8 }\end{array}$ & & & $\begin{array}{l}\text { B1 } \\
\text { B9 }\end{array}$ & \\
\hline B3 & B4 & B4 & & & B11 & & & B10 & B4 & & \\
\hline B4 & & & B9 & & B11 & B1 & B1 & B2 & & $\begin{array}{l}\text { B1 } \\
\text { B9 }\end{array}$ & \\
\hline B5 & B4 & B4 & & & & & & $\begin{array}{l}\text { B6 } \\
\text { B10 }\end{array}$ & B4 & & \\
\hline B6 & B4 & B4 & & & $\begin{array}{l}\text { B8 } \\
\text { B11 }\end{array}$ & & B8 & & B4 & & \\
\hline B7 & & & & $\begin{array}{l}\text { B5 } \\
\text { B6 }\end{array}$ & & & & & & $\begin{array}{l}\text { B5 } \\
\text { B6 }\end{array}$ & B6 \\
\hline B8 & & & & $\begin{array}{l}\text { B5 } \\
\text { B6 }\end{array}$ & & & & & & $\begin{array}{l}\text { B5 } \\
\text { B6 }\end{array}$ & B6 \\
\hline B9 & & B4 & & & B11 & B1 & B1 & B10 & & & \\
\hline B10 & & & & & $\begin{array}{l}\text { B8 } \\
\text { B11 }\end{array}$ & B8 & B8 & & & & \\
\hline B11 & & & & B5 & & B5 & & & & B5 & \\
\hline
\end{tabular}


Table 5 Final reachability matrix

\begin{tabular}{llllllllllll}
\hline & B1 & B2 & B3 & B4 & B5 & B6 & B7 & B8 & B9 & B10 & B11 \\
\hline B1 & & & & 1 & 1 & 1 & 1 & 1 & & 1 & 1 \\
B2 & 1 & & 1 & 1 & 1 & 1 & 1 & 1 & 1 & 1 & 1 \\
B3 & 1 & 1 & & 1 & 1 & & & 1 & 1 & 1 & 1 \\
B4 & 1 & 1 & 1 & & & 1 & 1 & 1 & 1 & 1 & 1 \\
B5 & 1 & 1 & & 1 & & 1 & & 1 & 1 & 1 & 1 \\
B6 & 1 & 1 & & 1 & 1 & & 1 & 1 & 1 & 1 & 1 \\
B7 & & & & 1 & 1 & 1 & & 1 & & 1 & 1 \\
B8 & & & & 1 & 1 & 1 & 1 & & & 1 & 1 \\
B9 & 1 & 1 & 1 & 1 & & 1 & 1 & 1 & & 1 & 1 \\
B10 & & & & & 1 & 1 & 1 & 1 & & & 1 \\
B11 & & & & 1 & 1 & 1 & & & & 1 & \\
\hline
\end{tabular}

\subsection{MICMAC analysis}

MICMAC is an established methodology to analyze the impact of variables/elements measured by relationships and is useful to highlight the key barriers that hinder the repurposing of manufacturing plant. The method results in a graphical representation of the barriers in four quadrants (autonomous, dependent, linkage and driving) based on dependence of each barrier. The driving and dependency are calculated from the summation of rows and columns
Fig. 2 Digraph showing direct and transitive links between barrier

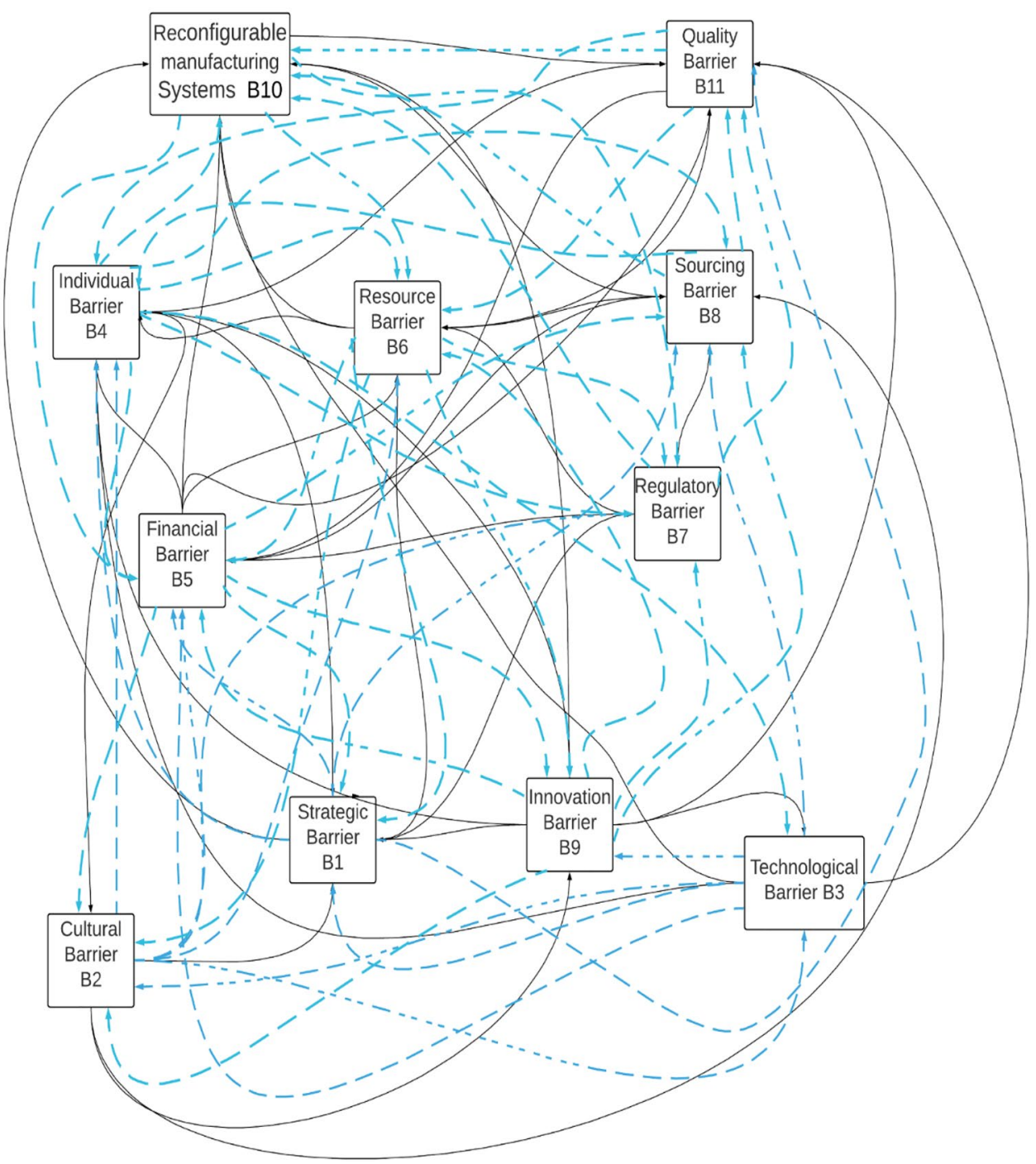


Fig. 3 TISM model obtained through this study

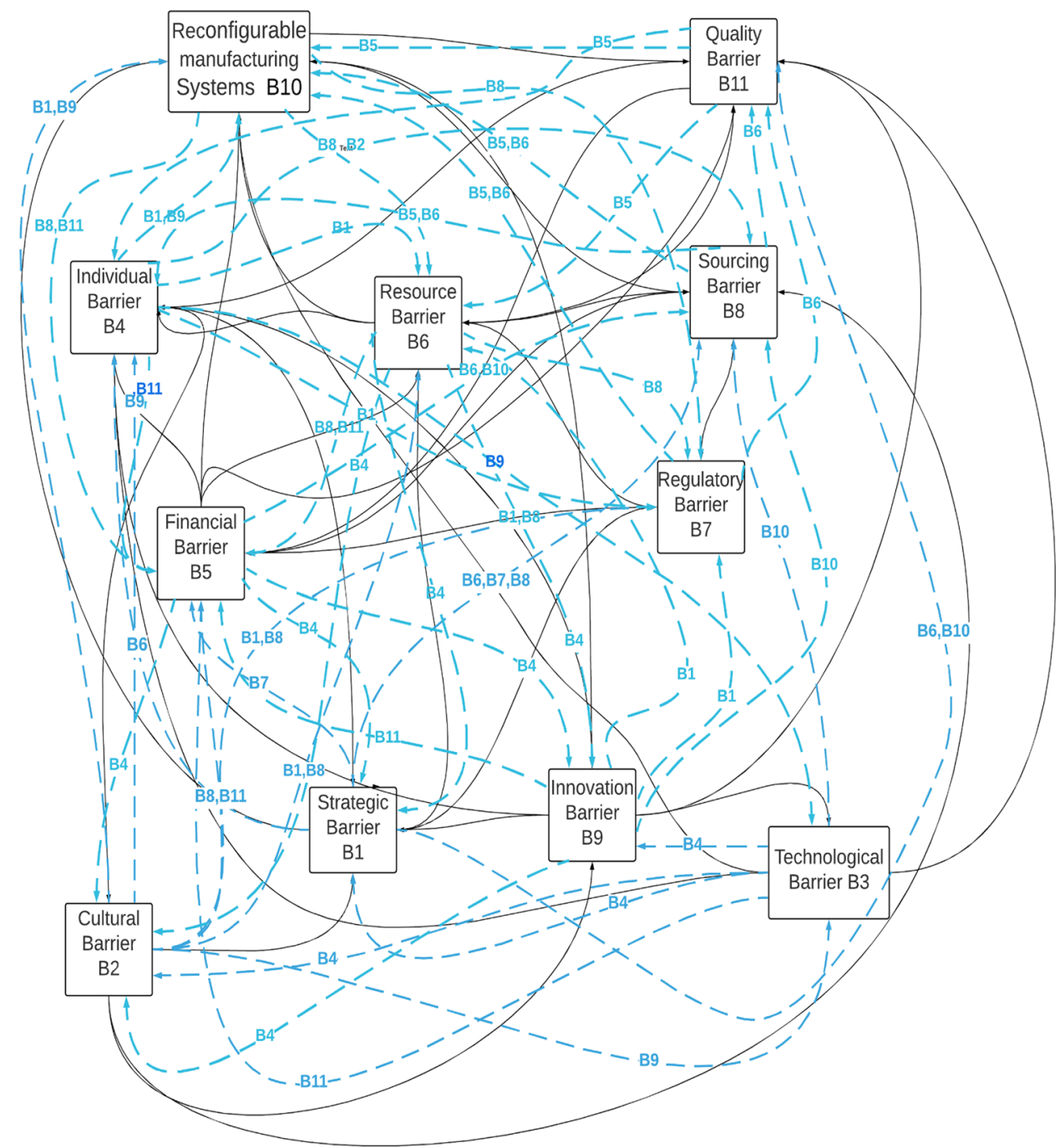

from the final matrix. The graph is split into 4 groups, each depicting level in precise classification. The first quadrant represents the autonomous elements, which are the barriers having low driving and dependence powers. The second quadrant consists of weak drivers but strongly dependent in nature. Barriers possessing high driving with high dependence power are placed in the third quadrant. The fourth quadrant represents the driving elements which possess low dependency with high driving force.

For MICMAC analysis, the driving power and dependence of each of the 11 barriers is tabulated which is achieved by simple summation of binary results from the Final Reachability Matrix. The nature of reachability matrix simplifies calculation of needed parameters to numbers which are plotted and segregated to quadrants. The driving power for barrier Bi is obtained by adding row-wise (horizontal) cells while dependence for $\mathrm{Bi}$ is obtained by column-wise (vertical) summation. i.e. Row-wise (horizontal) summation of $\mathrm{Bi}=$ Driving Power.

Column-wise (vertical) summation of $\mathrm{Bi}=$ Dependency Power.

Barrier B3 is used to depict sample calculation.

Driving Power $=\Sigma$ (binary inputs in row B3 in Table 4)

$=1+1+0+1+1+0+0+1+1+1+1$

$=8$

Dependence Power $=\Sigma$ (binary inputs in column B3 in

Table 4)

$=0+1+0+1+0+0+0+0+1+0+0$

$=3$

Driving power as well as dependency of each barrier is shown in Table 7. The scatter diagram is plotted with $\mathrm{X}$-axis representing Driving Power and Y-axis the Dependency. Data for MICMAC study is categorized by dividing the graph into four quadrants (autonomous, dependent, linkage and driving). Each quadrant has specific behavior which is followed 


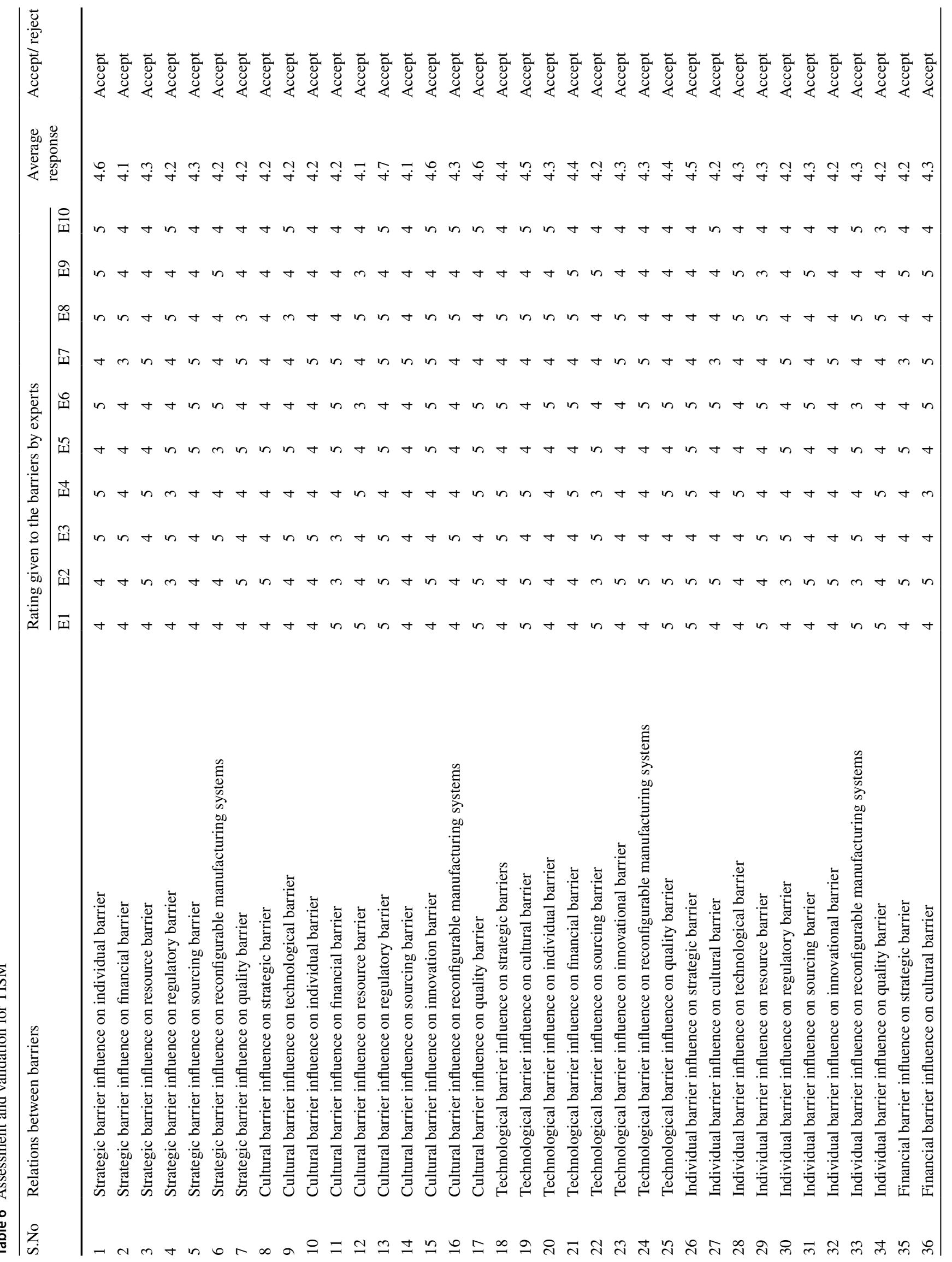




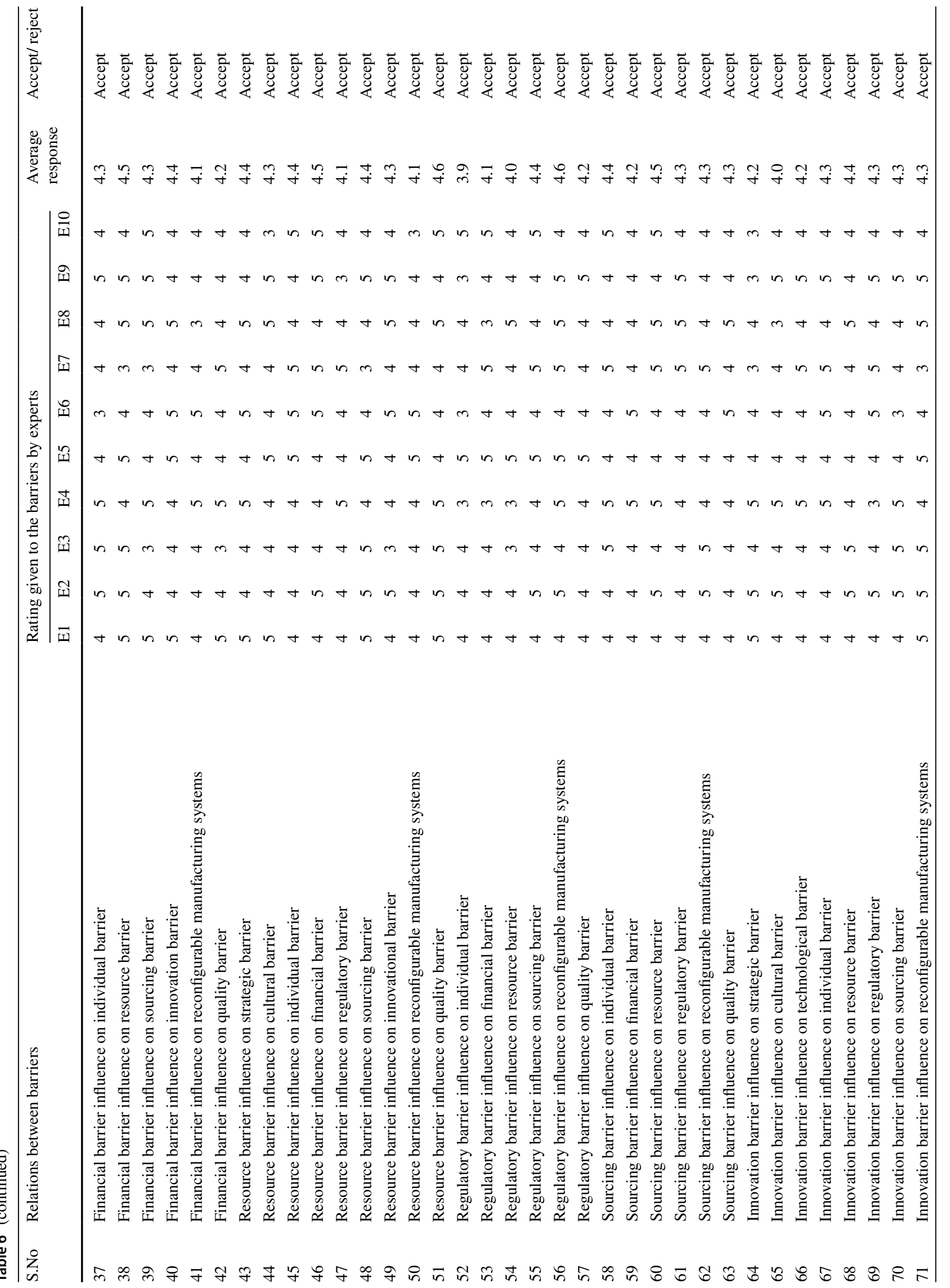




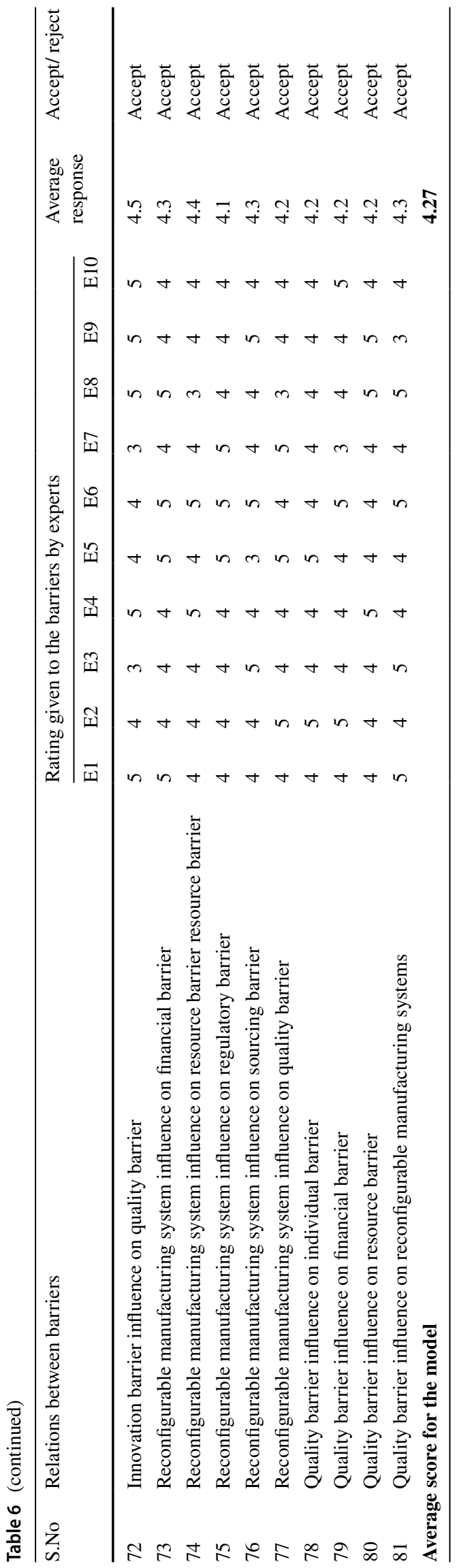

by any dataset present in it which furthers the study enabling documentation of nature of each barrier and study of degree of their impact on the manufacturing plant. Table 6 represents the driving and dependency of each barrier B1 to B11. The MICMAC analysis shows different categories of barriers in Fig. 5.

\section{Result and discussions}

A TISM model is obtained with the barriers segregated into 4 level based on their influence.

Level 1 Level 1 consists of the least influential barrier and hence are placed on top of the TISM chart. It consists of two barriers that are reconfigurable manufacturing system (B10) and quality barrier (B11) which means these barriers least affect other barriers but may be influences by other barriers the most.

Level 2 Level 2 consists of three barriers which are Individual (B4), Resource barrier (B6) and Sourcing Barrier (B8). Obtaining raw material and constant fluctuations in market in in terms of raw material availability customer, supply and demand proves a hindrance to adoption of repurposing a manufacturing plant.

Level 3 This level consists of two barriers Financial(B5) and regulatory barrier (B7). Constantly adapting government policy and trade policy on a global and national level with the need of capital and finance influence the repurposing chain.l

Level 4 This consists of three barriers which are strategic (B1) cultural (B2) and technological (B3) and innovational barriers(B9). These are the most influential barriers which provide strong and multiple transitive and direct links with other barriers which are responsible for the majority of network. With no proper technology it becomes very difficult to predict future demand, supply of raw material and manufactured product and market state. Clear organization goals with a proper structure and people's attitude toward the implementation of necessary changes at top management level and employee level is important for successful adoption of repurposing.

According to the developed TISM model Strategic (B1) Cultural (B2), Technological (B3) and Innovation Barrier (B9) are the most influential barrier and need to be eliminated first so the repurposing is as efficient as possible with least number of resources spent. Financial (B5) and regulatory barrier (B7) also have a strong drivability power but they are more influenced compared to the afore mentioned 4 barriers. Managers should focus on tackling these barriers by 
Fig. 4 Validated TISM model

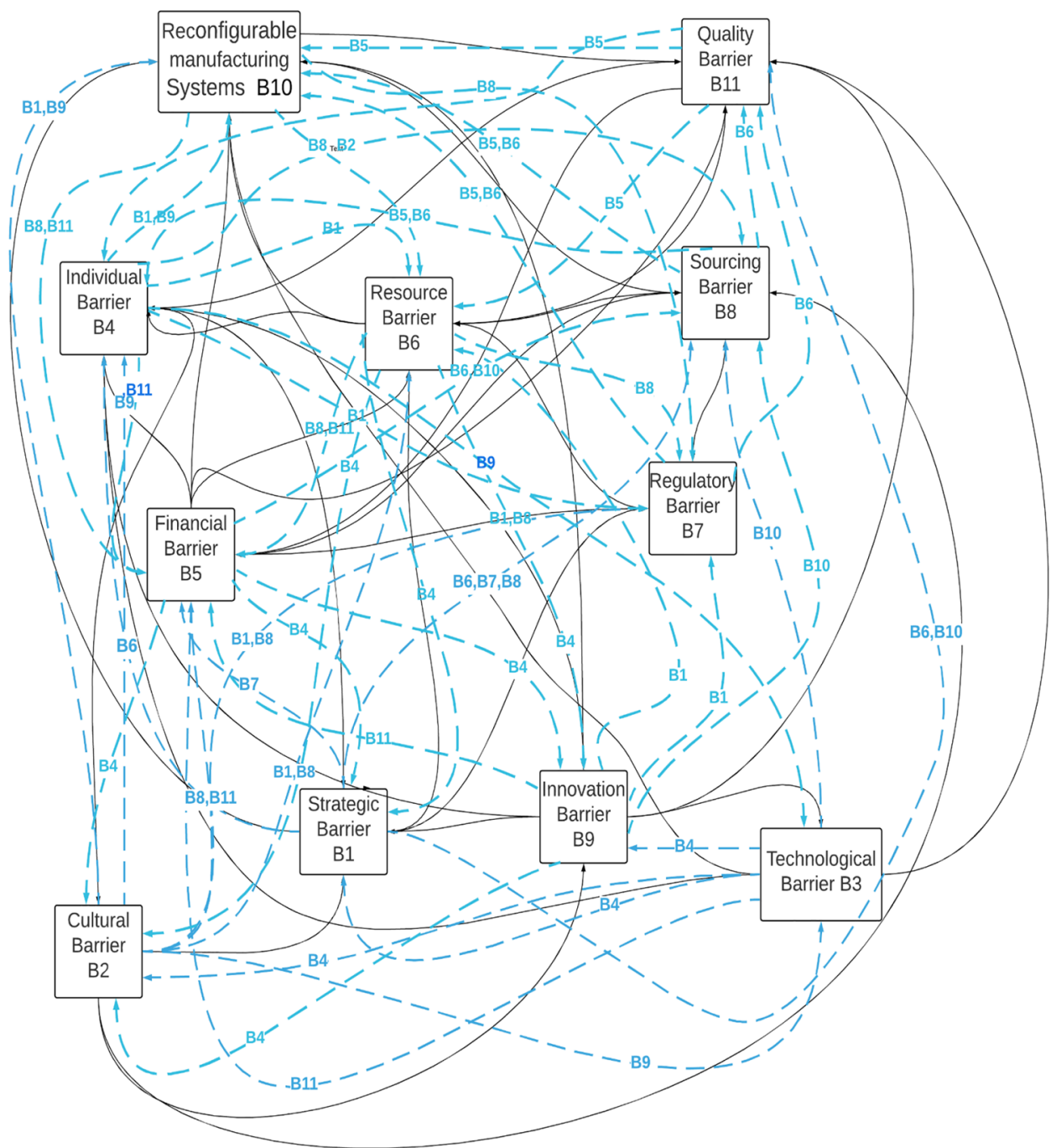

researching on the available government subsidiary or policies that might reduce the monetary burden. Market should be properly analyzed along with the available resources, preferably with the help of an economist or business analyst in order to eliminate Resource (B6) and Sourcing barrier (B8) which have low but significant influence on repurposing manufacturing plant. Quality barrier (B11) is the most affected barrier and managers can use this barrier to check the efficiency of repurposing that has been adopted. If the quality of the repurposed product/service up to standards that implies that the adopted repurposed model is efficient and effective.

According to previous studies done in the context of small and medium sized entrepreneurship by Gaikwad et al. (2020), top five barriers based on priority were effective management styles, fitting selection of management for effective training, accurate choice of tools and techniques, effective management and establishing of strategic planning, respectively which can be compared and are covered in the drivable barriers found in this study which are strategic, cultural and technological barriers. Studies done on manufacturing during the Covid-19 pandemic to bring out enablers and barriers based on survey of the people who are actively engaged in the manufacturing plant also result in similar conclusions (Hobbs 2020; Chowdhury et al. 2020). Respondents of the survey identified various barriers and top three influential barriers were organizational flexibility, skill level of the employees and technological hinderance (Okorie et al. 2020) to which similarities can be draw upon the barriers identified in this study. According to Baig et al. (2020) barriers related to managerial, sectoral and suppliers were the most important which can directly be contrasted to the results of this study.

\subsection{Theoretical contributions}

This research not only provides a multi-dimensional contribution to the limited existing knowledge in repurposing of a manufacturing plant but also gives insight on barriers and adoption in repurposing manufacturing plant. The research 
Fig. 5 Graph between dependence and driving power

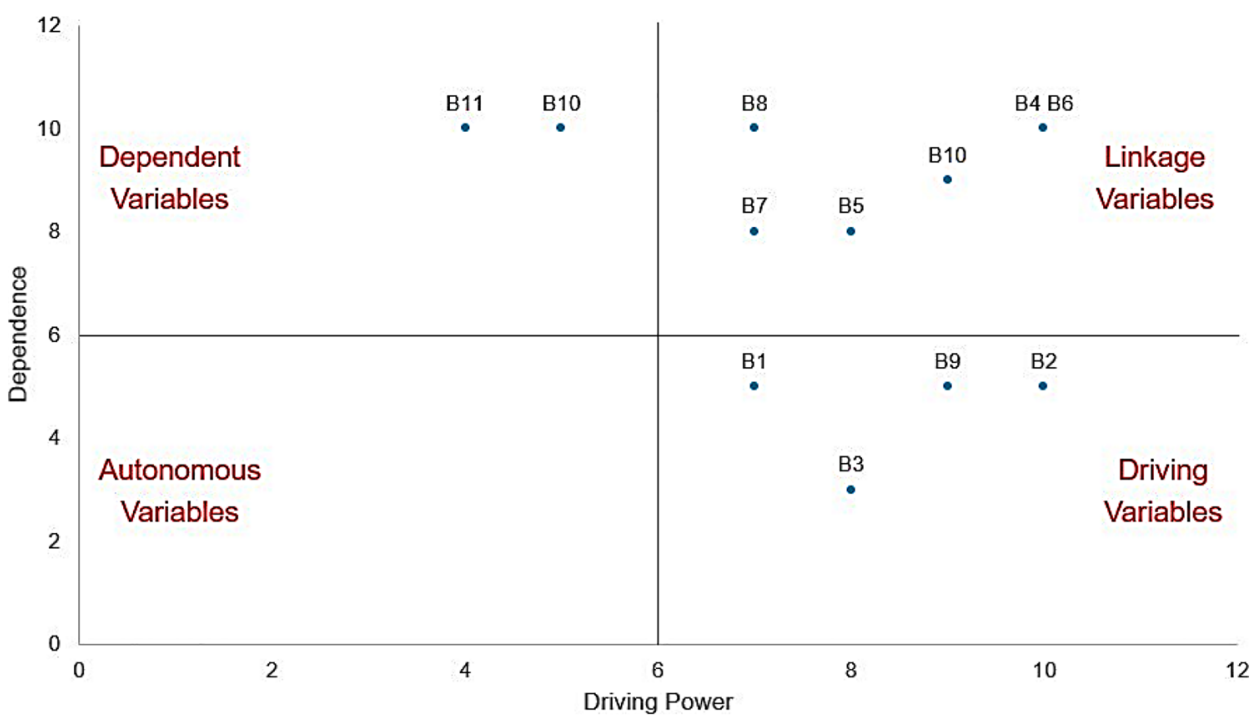

explains and explores the significant barriers to the adoption of repurposing in manufacturing plant. It established and contextual relationship between all the identified barriers using TISM and MICMAC analysis. None of the existing research adopts this model for the classification and relation establishment of the barriers. MICMAC analysis outputs the relative drivability and dependency of the barriers and they were divided into different categories which are autonomous barriers, independent barriers, dependent barriers and linkage barriers to understand their nature.

Based on the data collected and help of experts, barriers were ranked based on their driving and dependence powers and were categorized into 4 levels. the leveling of barriers and their interconnections will help researchers better understand their connections and relationships. As a result, this research not only provides a strong methodological and contextual contribution with the help of TISM and MICMAC but also gives researchers a sense of links of the barriers across various levels.

\subsection{Practical contributions}

In case of emergencies and sudden pandemic outbreaks that affect the production, supply and demand of a manufacturing plant and it becomes necessary to adopt manufacturing practices that will ensure the survivability of the plant. The adoption of repurposing the manufacturing plant to meet the supply-demand or alter production by manufacturing of a new or similar product or by reducing the manufacturing time will not only ensure the survivability of the plant.
In case of such unprecedent times where widespread has occurred affect the production, supply chain where it affects the market equilibrium. It becomes necessary to adopt new and different manufacturing practices. The processes of repurposing are actually to help the manufacturing plants come out of repercussions of the widespread by modifying their existing practice and business model to a new model which synchronizes with the new normal. To increase the efficiency and survivability of the plant. As a plant manager, they need to modify the existing operations, keep a check on all the specifications and make changes accordingly, need to see whether the production of new product can be done in the existing manufacturing systems, are the systems reconfigurable and making changes in business model so that supply and demand can be met easily without any hinderance.

The TISM model developed and various established relations between the barriers will help the plant managers and engineers to develop an appropriate plan and policy for the manufacturing plant to ensure its sustainability throughout and after repurposing. By segregating and diving the barriers into 4 level based on their drivability and dependency plant managers and engineers can be prioritize to overcome barriers based on their level and rank provided. Diving the barriers into 3 categories i.e., dependable, linkage and driving provides clarity to the barrier in terms of its type and priority that needs to be given. Level 1 (Reconfigurable Manufacturing systems and Quality barrier) barriers are most vulnerable but also have very low driving power. Managers should not concentrate and prioritize them at the
Table 7 Driving power and dependency power of barriers

\begin{tabular}{llllllllllll}
\hline Barrier & B1 & B2 & B3 & B4 & B5 & B6 & B7 & B8 & B9 & B10 & B11 \\
\hline Driving power & 7 & 10 & 8 & 9 & 8 & 9 & 7 & 7 & 9 & 5 & 4 \\
Dependency power & 5 & 5 & 3 & 9 & 8 & 9 & 7 & 9 & 5 & 10 & 10
\end{tabular}


beginning of repurposing instead should focus on eliminating level 4 barriers (Strategic, Cultural, Technological and innovational barrier). Manufacturing plant managers and engineers should incorporate techniques and practices that overcome these barriers based on the priority.

\section{Conclusion}

This research identifies the barriers in successful repurposing of the manufacturing plant. The interrelations of these barriers along with influence, dependence and drivability power were established and the barriers were ranked relatively based on the above factors. A relative relation has been developed between these barriers. Links have been established between the barriers that show direct and transitive relationships which establish the influence or dependency of one barrier on another and so has be charted on the TISM model. The reasons for the transitive link and direct links have been discussed and analyzed which further enables the clearer assessment of repurposing. Barriers classified on various levels and barriers on level 4 are the most foremost barrier that need to be overcome. These barriers influence the repurposing manufacturing chain the most and the other barriers act as the connection variable in the process. From the MICMAC analysis the barriers have been classified into four which helps to identify the impact of these barriers these quadrats and the barriers in them are as follows.

Driving variables For the successful adoption of the repurposing of the manufacturing plant it is important to first overcome those barriers that have high drivability power and less dependency power, meaning these barriers affect the repurposing of the manufacturing plant to the greatest extent by having a direct impact or having transitive impact by influencing other barriers. These barriers are called driving barriers that fall in the fourth quadrant of the MICMAC graph. It is revealed that Strategical, cultural, technological and innovational barriers influence other barrier the most and have great driving power. These barriers play a foremost role by steering the direction of development of repurposing. Engineers and plant managers adopting repurposing should focus more on eliminating these hindrances first for smooth adoption of the process.

Linkage variables Barriers that fall in the third quadrant of the MICMAC graph fall under linkage variables. Barriers having high dependency and high drivability fall under this category. Individual financial resource regulatory and sourcing barrier come under this category. These barriers are crucial not only in terms of influencing other barriers but also because of the fact that these barriers get affected by others to greater extent. These barriers are unstable barriers because their impact and influence both depend on other barriers.

Dependable variables The barriers in the first quadrant of the graph come under dependable variables as these barriers have high dependency and low influence on other barriers. Quality and Reconfigurable manufacturing system come under this barrier as they quiet sensitive to adjustments. By the analysis of the relations the barriers with each other and along with the nature of each barrier, the clarity in successful adoption of repurposing in a manufacturing plant has improved. It contributes to the repurposing manufacturing plant literature (González-Sanguino et al. 2020) by giving it an TISM and structural based framework and assessment angle as a consequence of expert opinion and literature study. It is indicated that a manufacturing plants should adopt repurposing with a good organizational vision and a strong outline for the repurposing model along with qualitative and motivated workforce and top management which are willing to carry out the necessary adjustments. The adoption of latest technology without hesitation and good communication structure is crucial to the repurposing of the manufacturing plant. Consultation and discussions with experienced individuals in the fields before carrying out repurposing and incorporation of innovative strategies is necessary for smooth adoption of the repurposing of the manufacturing plant.

Limitations and future research direction Though TISM and MICMAC only provides a strong contextual relation between barriers, their impact is not mathematically quantized, only analyzed subjectively. Barriers have been ranked on a relative scale and not on an absolute scale. Barriers have been relatively ranked on the basis of their influence, drivability and dependence by MICMAC. Other factors can also be taken into consideration for example: ease to overcome a barrier, time taken to overcome the barrier, disruption caused by a barrier etc. which can similarly be used to conclude the significance of barriers. Respondents and experts were limited for research and had different backgrounds and with different experience. Grey theory can be used as it gives weight to experience of the experts in MICMAC. Fuzziness of the response by the experts can be assessed by fuzzy theory.

Respondents and experts were very limited for proper research and had different backgrounds and experience. It was difficult to recruit volunteers with knowledge and experience for this arduous task. The TISM model was created with the constraint of a small number of responses and is attributed to a need to devote more time to pair-wise comparisons and to provide interpretive reasoning for each pair available. Documenting contextual relationships and the rationale behind each was time-consuming. 
Similarly, there existed lack of literature and study material as well as meaningful practical applications connecting to the topic at hand. While the pandemic did lead to an increasing amount of research and review being conducted on repurposing, it was insufficient to provide ample context.

\section{Appendix}

Questionnaire

1. Respondent profile

a) Designation:

b) Company Name:

c) Major Responsibility:
Table 8 Selection of relevant barriers

\begin{tabular}{lll}
\hline S. No & Barriers & $\begin{array}{l}\text { Is it } \\
\text { relevant? } \\
\text { (Yes/No) }\end{array}$ \\
\hline 1 & Strategic Barrier (B1) & \\
2 & Cultural barrier (B2) & \\
3 & Technological barrier (B3) \\
4 & Individual barrier (B4) \\
5 & Financial barrier (B5) \\
6 & Resource Barrier (B6) \\
7 & Regulatory Barrier (B7) & \\
8 & Sourcing barrier (B8) \\
9 & Innovation barrier (B9) & \\
10 & Reconfigurable Manufacturing & \\
11 & System (B10) & \\
Add relevant barriers if necessary & \\
\hline
\end{tabular}

Table 8

Table 9

Table 10

Table 9 Identification of the significant relationships

S.No Relations between barriers

5: Strongly agree and 1: Strongly disagree

\begin{tabular}{llllllllll}
\hline E1 & E2 & E3 & E4 & E5 & E6 & E7 & E8 & E9 & E10
\end{tabular}

\footnotetext{
1 Strategic barrier influence on individual barrier

2 Strategic barrier influence on financial barrier

3 Strategic barrier influence on resource barrier

$4 \quad$ Strategic barrier influence on regulatory barrier

$5 \quad$ Strategic barrier influence on sourcing barrier

6 Strategic barrier influence on reconfigurable manufacturing systems

$7 \quad$ Strategic barrier influence on quality barrier

8 Cultural barrier influence on strategic barrier

9 Cultural barrier influence on technological barrier

10 Cultural barrier influence on individual barrier

11 Cultural barrier influence on financial barrier

12 Cultural barrier influence on resource barrier

13 Cultural barrier influence on regulatory barrier

14 Cultural barrier influence on sourcing barrier

15 Cultural barrier influence on innovation barrier

16 Cultural barrier influence on reconfigurable manufacturing systems

17 Cultural barrier influence on quality barrier

18 Technological barrier influence on strategic barriers

19 Technological barrier influence on cultural barrier

20 Technological barrier influence on individual barrier

21 Technological barrier influence on financial barrier

22 Technological barrier influence on sourcing barrier

23 Technological barrier influence on innovational barrier

24 Technological barrier influence on reconfigurable manufacturing systems

25 Technological barrier influence on quality barrier

26 Individual barrier influence on strategic barrier

27 Individual barrier influence on cultural barrier

28 Individual barrier influence on technological barrier
} 
Table 9 (continued)

S.No Relations between barriers
5: Strongly agree and 1: Strongly disagree

$\begin{array}{llllllllll}\text { E1 } & \text { E2 } & \text { E3 } & \text { E4 } & \text { E5 } & \text { E6 } & \text { E7 } & \text { E8 } & \text { E9 } & \text { E10 }\end{array}$

$29 \quad$ Individual barrier influence on resource barrier

30 Individual barrier influence on regulatory barrier

31 Individual barrier influence on sourcing barrier

32 Individual barrier influence on innovational barrier

33 Individual barrier influence on reconfigurable manufacturing systems

34 Individual barrier influence on quality barrier

35 Financial barrier influence on strategic barrier

36 Financial barrier influence on cultural barrier

37 Financial barrier influence on individual barrier

38 Financial barrier influence on resource barrier

39 Financial barrier influence on sourcing barrier

40 Financial barrier influence on innovation barrier

41 Financial barrier influence on reconfigurable manufacturing systems

42 Financial barrier influence on quality barrier

43 Resource barrier influence on strategic barrier

44 Resource barrier influence on cultural barrier

45 Resource barrier influence on individual barrier

46 Resource barrier influence on financial barrier

47 Resource barrier influence on regulatory barrier

48 Resource barrier influence on sourcing barrier

49 Resource barrier influence on innovational barrier

50 Resource barrier influence on reconfigurable manufacturing systems

51 Resource barrier influence on quality barrier

52 Regulatory barrier influence on individual barrier

53 Regulatory barrier influence on financial barrier

54 Regulatory barrier influence on resource barrier

55 Regulatory barrier influence on sourcing barrier

56 Regulatory barrier influence on reconfigurable manufacturing systems

57 Regulatory barrier influence on quality barrier

58 Sourcing barrier influence on individual barrier

59 Sourcing barrier influence on financial barrier

60 Sourcing barrier influence on resource barrier

61 Sourcing barrier influence on regulatory barrier

62 Sourcing barrier influence on reconfigurable manufacturing systems

63 Sourcing barrier influence on quality barrier

64 Innovation barrier influence on strategic barrier

65 Innovation barrier influence on cultural barrier

66 Innovation barrier influence on technological barrier

67 Innovation barrier influence on individual barrier

68 Innovation barrier influence on resource barrier

69 Innovation barrier influence on regulatory barrier

70 Innovation barrier influence on sourcing barrier

71 Innovation barrier influence on reconfigurable manufacturing systems

72 Innovation barrier influence on quality barrier

73 Reconfigurable manufacturing system influence on financial barrier

74 Reconfigurable manufacturing system influence on resource barrier resource barrier

75 Reconfigurable manufacturing system influence on regulatory barrier

76 Reconfigurable manufacturing system influence on sourcing barrier 
Table 9 (continued)

S.No Relations between barriers

5: Strongly agree and 1: Strongly disagree

\begin{tabular}{llllllllll}
\hline E1 & E2 & E3 & E4 & E5 & E6 & E7 & E8 & E9 & E10
\end{tabular}

\begin{tabular}{ll}
\hline 77 & Reconfigurable manufacturing system influence on quality barrier \\
78 & Quality barrier influence on individual barrier \\
79 & Quality barrier influence on financial barrier \\
80 & Quality barrier influence on resource barrier \\
81 & Quality barrier influence on reconfigurable manufacturing systems
\end{tabular}

Table 10 Professional and academic experts for model validation

\begin{tabular}{lll}
\hline Names & Affiliations & Institutions \\
\hline Expert 1 & Professor- Industrial and Production Engineering & Institute 'A' \\
Expert 2 & Professor- Supply Chain Management & Institute 'B' \\
Expert 3 & Associate Professor- Operation research & Institute 'C' \\
Expert 4 & Associate Professor- Industrial and System Engineering & Institute 'D' \\
Expert 5 & Associate Professor- Product Engineering & Institute 'E' \\
Expert 6 & Associate Professor- Product Engineering & Institute 'F' \\
Expert 7 & Assistant General Manager- Supply Chain & Company 'G' \\
Expert 8 & Senior manager- Logistics & Company 'H' \\
Expert 9 & Manager- Operations & Company 'I' \\
Expert 10 & Manager- Supply Chain & Company ' $\mathrm{J}$ \\
\hline
\end{tabular}

\section{References}

Alora A, Barua MK (2019) Barrier analysis of supply chain finance adoption in manufacturing companies. Benchmarking: An International Journal 26.\&nbsp;https://doi.org/10.1108/BIJ-08-2018-0232

Armani AM, Hurt DE, Hwang D, McCarthy MC, Scholtz A (2020) Lowtech solutions for the COVID-19 supply chain crisis. Nature Reviews Materials 5(6):403-406

Barbieri P, Bofelli A, Elia S, Fratocchi L, Kalchschmidt M, Samson D (2020) What can we learn about reshoring after Covid-19? Oper Manag Res 13. https://doi.org/10.1007/s12063-020-00160-1

Baig SA, Abrar M, Batool A, Hashim M, Shabbir R (2020) Barriers to the adoption of sustainable supply chain management practices: Moderating role of firm size. Cogent Business Management 7:1. https:// doi.org/10.1080/23311975.2020.1841525

Bauer T, Brissaud D, Zwolinski P (2017) Design for high added-value end-of-life strategies. In Sustainable Manufacturing (pp. 113128). Springer, Cham

Bekaert G, Engstrom E, Ermolov A (2020) Aggregate demand and aggregate supply effects of covid-19: A real-time analysis. Available at SSRN 3611399

Chowdhury MT, Sarkar A, Paul SK, Moktadir MA (2020) A case study on strategies to deal with the impacts of COVID-19 pandemic in the food and beverage industry. Oper Manag Res. https://doi.org/10.1007/ s12063-020-00166-9

Daniel J (2020) Education and the COVID-19 pandemic. Prospects, 49(1):91-96

Farooq MU, Hussain A, Masood T, Habib MS (2021) Supply Chain Operations Management in Pandemics: A State-of-the-Art Review Inspired by COVID-19. Sustainability 13(5):2504

Gaikwad SK, Paul A, Moktadir MA, Paul SK, Chowdhury P (2020) Analyzing barriers and strategies for implementing Lean Six Sigma in the context of Indian SMEs. Benchmarking: An International Journal 27:2365-2399. https://doi.org/10.1108/ BIJ-11-2019-0484.
Girubha J, Vinodh S, KEK V (2016) "Application of interpretative structural modelling integrated multi criteria decision making methods for sustainable supplier selection", Journal of Modelling in Management 11(2):358-388

González-Sanguino C, Ausín B, Castellanos MÁ, Saiz J, López-Gómez A, Ugidos C, Muñoz M (2020) Mental health consequences during the initial stage of the 2020 Coronavirus pandemic (COVID19 ) in Spain. Brain, behavior, and immunity 87:172-176

Gupta A, Coven J (2020) Disparities in mobility responses to COVID19. New York University

Hobbs JE (2020) Food supply chains during the COVID-19 pandemic. Can J Agr Econ 68(2):171-176

Ivanov D, Dolgui A (2020) A digital supply chain twin for managing the disruption risks and resilience in the era of Industry 4.0. Prod Plan Control. https://doi.org/10.1080/09537287.2020.1768450

Jain S, Lamba BV, Kumar S, Singh D (2020) Strategy for repurposing of disposed PPE kits by production of biofuel: Pressing priority amidst COVID-19 pandemic. Biofuels. https://doi.org/10.1080/ 17597269.2020.1797350

Jayan V, Ajan A, Mohan H, Manikutty G, Sasi D (2020) Design and development of a low-cost powered air-purifying respirator for frontline medical workers for COVID-19 response. IEEE 8th R10 Humanitarian Technology Conference pp. 1-6. https://doi.org/10. 1109/R10-HTC49770.2020.9356954

Karuppiah K, Sankaranarayanan B, Ali SM, Chowdhury P (2020) An integrated approach to modeling the barriers in implementing green manufacturing practices in SMEs. J Clean Prod 265:121737. https://doi.org/10.1016/j.jclepro.2020.121737

Kumar S, Vinodh S (2020) TISM for analysis of barriers affecting the adoption of lean concepts to electronics component manufacture. International Journal of Lean Six Sigma. https://doi.org/10.1108/ IJLSS-09-2018-0100

Liu W, Beltagui A, Ye S (2021) Accelerated innovation through repurposing: exaptation of design and manufacturing in response to COVID-19. RD Manag 
López-Gómez C, Corsini L, Leal-Ayala D, Fokeer S (2020) COVID19 critical supplies: The manufacturing repurposing challenge. UNIDO

Mathivathanan D, Mathiyazhagan K, Rana NP, Khorana S, Dwivedi YK (2021) Barriers to the adoption of blockchain technology in business supply chains: a total interpretive structural modelling (TISM) approach. Int J Prod Res. https://doi.org/10.1080/00207543.2020. 1868597

Mattevi M, Jones JA (2016) Food supply chain: are UK SMEs aware of concept, drivers, benefits and barriers, and frameworks of traceability?. British Food Journal

Okorie O, Subramoniam R, Charnley F, Patsavellas J, Widdifield D, Salonitis K (2020) Manufacturing in the Time of COVID-19: An Assessment of Barriers and Enablers. IEEE Eng Manage Rev 48(3):167-175

Prather KA, Wang CC, Schooley RT (2020) Reducing transmission of SARS-CoV-2. Science 368(6498):1422-1424

Qin X, Godil DI, Khan MK, Sarwat S, Alam S, Janjua L (2021) Investigating the effects of COVID-19 and public health expenditure on global supply chain operations: an empirical study. Oper Manag Res. https://doi.org/10.1007/s12063-020-00177-6

Rapaccini M, Saccani N, Kowalkowski C, Paiola M, Adrodegari F (2020) Navigating disruptive crises through service-led growth: The impact of COVID-19 on Italian manufacturing firms. Ind Mark Manage 88:225-237

Roy S, Paul A, Kashyap S, Jana A (2021) Ranking Barriers of Supply Chain Management by MCDM Method During Disaster Management: A Case Study of India. International Journal of System Dynamics Applications (IJSDA) 10(2):1-16
Schumacher R, Glew R, Tsolakis N, Kumar M (2021) Strategies to manage product recalls in the COVID-19 pandemic: an exploratory case study of PPE supply chains. Continuity Resilience Review. https://doi.org/10.1108/CRR-07-2020-0024

Shokrani A, Loukaides EG, Elias E, Lunt AJG (2020) Exploration of alternative supply chains and distributed manufacturing in response to COVID-19; a case study of medical face shields. Materials Design 192:108749. https://doi.org/10.1016/j.matdes. 2020.108749

Sindhwani R, Mittal VK, Singh PL, Aggarwal A, Gautam N (2019) Modelling and analysis of barriers affecting the implementation of lean green agile manufacturing system (LGAMS).\&nbsp;Benchmarking: An International Journal 26(2):498-529

Urbinati A, Franzo S, Chiaroni D (2021) Enablers and Barriers for Circular Business Models: an empirical analysis in the Italian automotive industry. Sustainable Production and Consumption 27:551-566. https://doi.org/10.1016/j.spc.2021.01.022

Vogelsang K, Liere-Netheler K, Packmohr S, Hoppe U (2019) Barriers to digital transformation in manufacturing: development of a research agenda

Zhu N, Zhang D, Wang W, Li X, Yang B, Song J, Tan W (2020) A novel coronavirus from patients with pneumonia in China, 2019. New England journal of medicine

Publisher's Note Springer Nature remains neutral with regard to jurisdictional claims in published maps and institutional affiliations. 